Research Article

\title{
Refined Time-Domain Buffeting Analysis of a Long-Span Suspension Bridge in Mountainous Urban Terrain
}

\author{
Bo Wu, ${ }^{1}$ Liang-Liang Zhang $\mathbb{D}^{1}{ }^{1}$ Yang Yang $\mathbb{D},{ }^{1}$ Lian-Jie Liu, ${ }^{2}$ and Zhi-Jun $\mathrm{Ni}^{1}$ \\ ${ }^{1}$ School of Civil Engineering, Key Laboratory of New Technology for Construction of Cities in Mountain Area, \\ Chongqing University, Chongqing 400045, China \\ ${ }^{2}$ Department of Highway Engineering, Chongqing Construction Science Research Institute, Chongqing 400017, China
}

Correspondence should be addressed to Liang-Liang Zhang; zll200510@126.com and Yang Yang; yy20052710@163.com

Received 8 January 2020; Revised 18 April 2020; Accepted 23 May 2020; Published 29 June 2020

Academic Editor: Claudio Mazzotti

Copyright (c) 2020 Bo Wu et al. This is an open access article distributed under the Creative Commons Attribution License, which permits unrestricted use, distribution, and reproduction in any medium, provided the original work is properly cited.

\begin{abstract}
The field measurements, wind tunnel tests, and numerical calculations are utilized to conduct refined time-domain buffeting analysis of a long-span suspension bridge. The wind characteristics in the mountainous urban terrain are obtained through longterm field measurements. The aerostatic force coefficients (AFCs) and aerodynamic admittance functions (AAFs) are experimentally tested in a wind tunnel. The fluctuating wind fields on the bridge are simulated by the spectral representation method. Finally, the buffeting responses are calculated in ANSYS. The influences of AAF, turbulence power spectrum, and angle of attack (AoA) on the buffeting responses are evaluated, which highlight the inaccuracies caused by empirical simplifications. To improve the buffeting performance without a considerable extra budget, minor modifications are introduced to the original design configuration. The buffeting responses are slightly reduced by increasing the ventilation rate of guardrails, and the control efficiency is better when concurrently moving the inspection rails inward. Besides, the buffeting responses are increased when considering the roughness on the girder surface. The influence mechanism of the countermeasure is analyzed using the Computational Fluid Dynamics (CFD) method, which mainly lies in the dissipation of turbulence energy around the girder. The findings can contribute to the wind-resistant analysis and optimization design for similar bridges.
\end{abstract}

\section{Introduction}

Suspension bridges have shown the best-spanning capability among various bridge structures. With spans increasing, the newly built bridges become more and more flexible and hence more sensitive to wind loadings. As a result, high-level windinduced vibrations are frequently observed on long-span bridges. There are mainly four kinds of wind-induced vibrations occurring on bridges, including flutter, buffeting, galloping, and vortex-induced vibration. Buffeting is induced by the wind speed fluctuations of natural wind, which is one of the inherent characteristics of the atmosphere. Therefore, buffeting occurs daily on long-span bridges, which is different from the other three kinds of vibrations. Although buffeting will not cause catastrophic damage, it affects the fatigue life of the bridge and reduces the driving comfortableness [1]. Since the service period of a long-span bridge is designed to be several decades or even more than 100 years, the bridge is usually inevitable to suffer from strong buffeting responses. Therefore, it is indispensable to properly evaluate the buffeting responses of long-span bridges.

The buffeting analysis can be conducted either in frequency domain or in time domain. The frequency-domain analysis is based on the linear hypothesis, and only a limited number of vibration modes can be included to obtain only the statistical values of the buffeting responses. To consider the nonlinearities caused by geometric, material, and aerodynamic effects, the time-domain analysis should be conducted for long-span bridges. Moreover, time histories of buffeting displacements are available. The time-domain method is conducted in three steps: (i) generating the time histories of fluctuating wind at different locations on the bridge, (ii) determining the time-domain buffeting loadings, and (iii) calculating buffeting responses. 
The time histories of fluctuating wind are usually simulated using the spectral representation method, by adopting the power spectrum functions of fluctuating wind as the input [2-5]. Therefore, the selection of the power spectrum will significantly affect the accuracy of the wind field simulation results. Due to the difficulties in conducting comprehensive field measurements at the bridge site, most existing researches simulated the fluctuating wind field through empirical power spectrum models, such as Kaimal spectrum and Panofsky spectrum recommended in the Wind-Resistant Design Specification for Highway Bridges [6] (Professional Standard of China for short). However, the empirical models are generally subjected to some simplifications and cannot always well accord with the buffeting analysis in different geomorphic terrains. In a mountainous area with complex terrains, the wind field is of high turbulence and large angles of attack (AoAs) [7], which cannot be accurately described by the Kaimal spectrum and Panofsky spectrum.

For determining buffeting forces, Davenport [8] proposed the quasi-steady theory for long-span bridges under turbulent winds. According to the Davenport Chain [9], the buffeting performance of a bridge relies directly on the aerodynamic characteristics. The aerodynamic admittance function (AAF) may be the most important aerodynamic parameter as it relates wind characteristics to buffeting loadings and reflects the unsteady features [10-12]. In the current buffeting analysis, the Sears function [13] or Davenport function [8] is widely adopted as the simplified AAF when the measured one is not available. However, the threedimensionality of turbulent wind is neglected in the Sears function. Moreover, the present AAF models are frequency dependent and cannot be directly considered in time domain [14]. Therefore, the AAF is usually taken as 1 without considering the unsteadiness of buffeting forces in most of the time-domain buffeting analysis $[15,16]$. Considering the importance of AAF, the above empirical simplifications will lead to inaccurate predictions of the buffeting responses during the design stage [17-19]. Therefore, the deviations should be further studied by experimentally measuring the actual AAF of the bridge [20].

The vertical angle of attack (AoA) is the angle between the mean wind direction and the horizontal plane. Most of the previous studies $[21,22]$ are concentrated on AoA of $0^{\circ}$ when calculating buffeting responses. This is different from the natural wind characteristics at the bridge site, where the AoA is unsteady and complicated in time domain [7]. Since the buffeting forces on the bridge will change with AoA, the results at AoA of $0^{\circ}$ cannot evaluate the buffeting behavior of the bridge veritably. Therefore, the influence of AoA should be conducted.

To reduce the possibility of wind-induced vibrations during operation, the aerodynamic behavior of the bridge should be optimized in the design stage $[23,24]$. The suppression of vortex-induced vibration, galloping, and flutter has been widely conducted by a series of aerodynamic countermeasures [25]. Ming et al. [26] and Tao et al. [15] conducted parametric studies to investigate the control efficiency of multiple tuned mass dampers (MTMD) on the buffeting responses of a long-span triple-tower suspension bridge. However, considerable free space within the bridge girder is required to install the MTMD, which is not always available. Moreover, the MTMD will also increase the construction budget from an economic view of point. Taken together, the control countermeasures should be designed by synthetically considering the efficiency and budget. According to [23, 27], the flow field around a bridge structure can be substantially changed by modifying its geometrical shape. Of particular attention is that the overall dimensions of the bridge have been established before evaluating its aerodynamic behavior. In this regard, we consider the following concerns when conducting geometrical modifications to improve the buffeting performance of a long-span bridge: (i) the geometrical modifications should not cause considerable reformulations of the initial design and (ii) the extra delays and costs should be controlled.

Taking a long-span suspension bridge in mountainous urban terrain as a typical example, the sensitivity of buffeting responses to major aerodynamic parameters and geometrical modifications is analyzed in the present study. The buffeting analyses are conducted in the time domain based on the computer-aided finite element method. To obtain accurate results, the wind characteristics at the bridge site are measured to set up the basis for the following parametric studies, which are presented in Section 2. In Section 3, the aerodynamic loadings acting on the bridge are determined through both experimental and numerical approaches. In Section 4, the influences of AAF, turbulence power spectrum model, and AoA are estimated. Then, simple and efficient schemes by minor geometrical modifications of the main girder are proposed to suppress the buffeting responses. The control mechanisms are explained, from a physical point of view, based on the Computational Fluid Dynamics (CFD) models of the main girder. Finally, a summary of the main finding is given in Section 5.

\section{Wind Characteristics at the Bridge Site}

2.1. Description of the Bridge. CUN-TAN Yangtze Bridge is a long-span suspension bridge across the Yangtze River. It is located in a mountainous city in the southwest region of China. As shown in Figure 1, the terrain around the bridge is characterized by crowded high buildings and rugged mountains. The bridge consists of the main span $(880 \mathrm{~m})$ and two approach spans $(250 \mathrm{~m}+250 \mathrm{~m})$. The towers are $100 \mathrm{~m}$ in height, and the sag-to-span ratio of the main cable is 1/8.8. The streamlined steel-box girder is employed as the bridge deck, and the width and height are $42 \mathrm{~m}$ and $3.5 \mathrm{~m}$, respectively. The width to depth ratio of the main girder is 12 , which is one of the largest ratios for suspension bridges. The main dimensions of the bridge are shown in Figure 2.

2.2. Field Measurement System. The measuring station is set up on the construction crane of the south tower, with the sensors arranged on the outstretched steel brackets to eliminate any disturbance caused by the structures and 


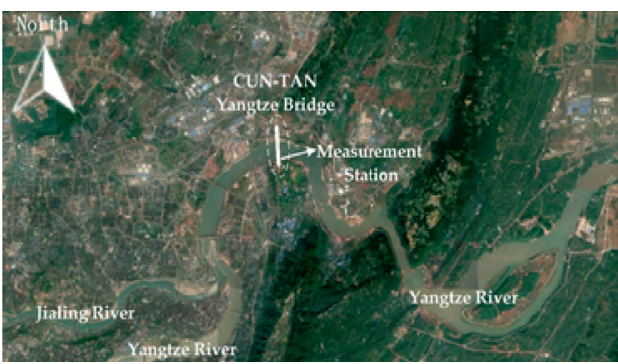

(a)

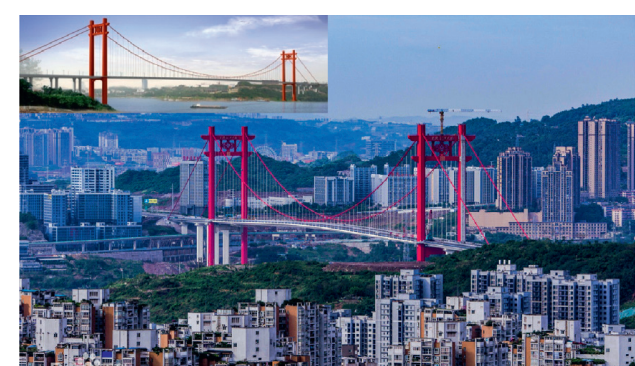

(b)

Figure 1: (a) Geographical location of the bridge. (b) Overlooking view of the bridge.

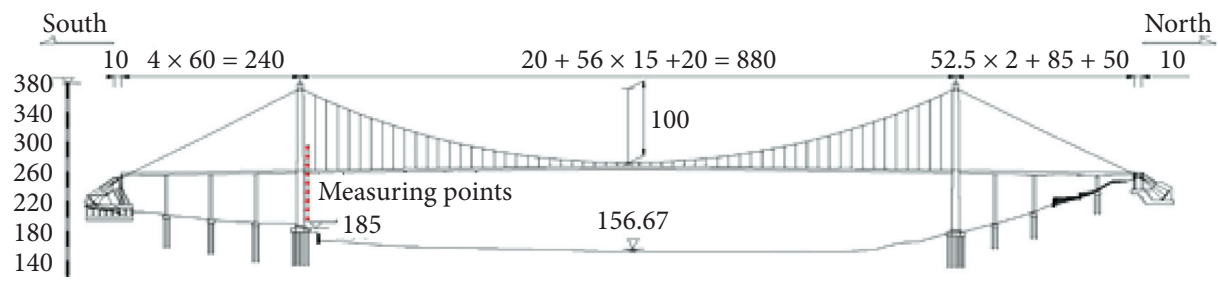

(a)

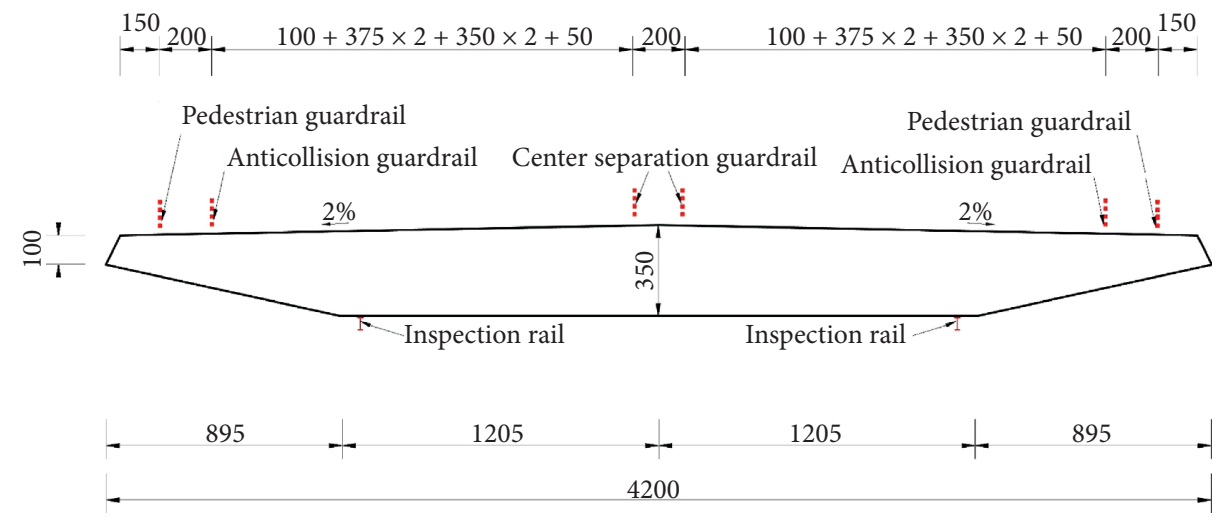

(b)

Figure 2: Dimensions of the bridge: (a) elevation view; (b) main girder.

vibrations of the bridge. The sensor system consists of 9 monitoring points named $P 1-P 9$. The first point $P 1$ is $10 \mathrm{~m}$ above the ground, and $P 2-P 9$ are placed at an interval of $12 \mathrm{~m}$. This layout is intentionally selected to make the point $P 6$ at the girder height. The 3-cup anemometer sensors are installed at each measuring point to measure the mean wind characteristics. To measure the turbulence characteristics, an extra sensor, Yong 81000 ultrasonic anemometer, is placed at P6 to measure the data with the sampling frequency of $10 \mathrm{~Hz}$. The measuring system is shown in Figure 3. The measurement is conducted during constructing the bridge. To validate the reliability of the 3-cup sensors, the wind speeds measured using the ultrasonic anemometer and the 3-cup anemometer sensor are compared in Figure A1 in Supplementary A.

2.3. Wind Field Characteristics. Both the speed and direction of the fluctuating wind can be obtained from the measuring data. During the measuring period, the expectation of effective data at $P 6$ is $23.96 \mathrm{~m} / \mathrm{s}$, with a standard deviation of $2.29 \mathrm{~m} / \mathrm{s}$. The reference mean wind speed $(U)$ is calculated for 10 -min intervals using "peaksover-threshold method" [28]. Considering a recurrence interval of 100 years, the reference mean wind speed is calculated to be $42.61 \mathrm{~m} / \mathrm{s}$ at the girder height. After obtaining the mean speeds of all the measuring points, the wind speed profile is introduced to describe the distribution of wind speed along the height above the ground. According to [6], the mean wind speed profile follows the exponential model in

$$
\ln \frac{U_{1}}{U_{2}}=\beta \ln \frac{Z_{1}}{Z_{2}},
$$

where $Z_{1}$ and $Z_{2}$ are the heights above the ground and $U_{1}$ and $U_{2}$ are the mean speeds at $Z_{1}$ and $Z_{2}$, respectively. The index $\beta$ is a dimensionless exponent depending on the terrain. Based on the mean wind speeds of $P 1-P 9, \beta$ is fitted to be 0.166 . 


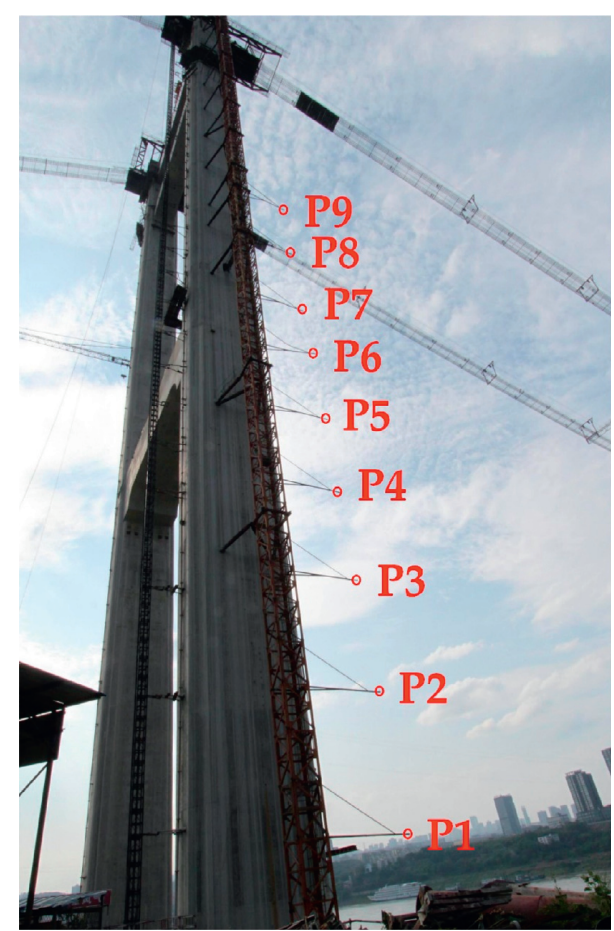

FIGURE 3: The measurement station where the sensors are installed on the construction crane of the south tower and $P 1-P 9$ denote the measuring points.

The vertical AoA is the angle between the mean wind direction and the horizontal plane. Since the buffeting forces on the bridge will change with AoA, it is necessary to describe the AoA conditions at the bridge site. For each point, the AoA is calculated at each 10-min interval. The AoA at the girder height $(P 6)$ is in the range $\left(-16.3^{\circ}-+15.4^{\circ}\right)$ with the average $-2.6^{\circ}$, which means that the mean wind is generally downward against the girder plane. In particular, the AoAs with a confidence interval of $95 \%$ are in the range $\left(-8^{\circ}-+5^{\circ}\right)$.

The turbulence power spectra of the longitudinal and the vertical components are estimated using the data measured by Yong 81000 ultrasonic anemometer at P6. To keep the stationarity of calculated spectra, the data with relatively high wind speeds $(>10 \mathrm{~m} / \mathrm{s})$ and stable directions are chosen for the analysis [29]. The 10-min recording data are analyzed in the frequency domain by Welch spectral estimation method. The parameters in the mathematical model of the spectra are then obtained by a nonlinear least-square fit of the measured results. In the fitting process, the target model for longitudinal and vertical fluctuating wind takes Kaimal model and Panofsky model, respectively, which are recommended in [6] and shown in

$$
\left\{\begin{array}{l}
\frac{n S_{u}(z, n)}{u_{*}^{2}}=\frac{A_{u} f}{\left(1+B_{u} f\right)^{5 / 3}}, \\
\frac{n S_{w}(z, n)}{u_{*}^{2}}=\frac{A_{w} f}{\left(1+B_{w} f\right)^{2}},
\end{array}\right.
$$

where $S_{u}(z, n)$ and $S_{w}(z, n)$ are the power spectra of longitudinal and vertical components. $u_{*}^{2}=(\mathrm{KU}(z) /$ $\left.\ln \left(z / z_{0}\right)\right)$ is the friction velocity, wherein $K \approx 0.4$ and $z_{0}=0.01$ is the roughness height. $\mathrm{n}$ is the natural frequency, $f=n z / U(z)$ is the Morin coordinate. $A_{u}, A_{w}, B_{u}$, and $B_{w}$ are the parameters that need to be fitted. In the Kaimal model, $A_{u}$ and $B_{u}$ are 200 and 50, respectively; in the present study, the fitted values based on the weighted averaging of all the effective data are 80.254 and 24.359, respectively. In the Panofsky model, $A_{w}$ and $B_{w}$ are 6 and 4 , respectively. In the fitting spectrum, they are 8.887 and 5.207.

Taking the strong wind event measured on Oct. 15th, 2014, as example, the measured power spectra and the fitted models for longitudinal and vertical fluctuating winds are shown in Figure 4. The recommended models are also depicted for comparisons. As shown in the figure, the measured $S_{u}(z, n)$ is significantly higher than Kaimal model in the high-frequency range, while the measured $S_{w}$ $(z, n)$ is higher than Panofsky model in low-frequency region. Accordingly, the wind field characteristics of a mountainous urban area cannot be accurately described by [6], due to the large deviations between the recommended and measured power spectrum models. Therefore, to accurately obtain the buffeting responses, the current analyses are based on the measured wind characteristics. More details of the wind field characteristics can be found in Supplementary A.

\section{Wind Loadings on the Bridge}

3.1. Section Models and Case Configurations. Wind tunnel tests are conducted to obtain the needed parameters in timedomain buffeting analysis. The section models are manufactured using high-quality light wood and plastic. In the static loading tests (Section 3.2), the scaling ratio of the model is $1 / 60$, with the width and depth being $0.700 \mathrm{~m}$ and $0.058 \mathrm{~m}$. In the AAF identification tests (Section 3.3), the scaling ratio of the model is $1 / 300$, which is intentionally designed considering the measuring range of the high-frequency force balance (HFFB).

To improve the buffeting performance of the bridge, minor geometric modifications are introduced to the original final design sectional model. The details of the main girder configuration for each case are shown in Table 1 (at 1/60 scaling ratio for instance), while the reasons for such modifications will be discussed in Section 4.3. For convenience, the construction configuration is labeled as Case 0 , and the original final design is labeled as Case 1. With regard to Case 2, the pedestrian guardrails are changed from Type I to Type II, and the details of each type are shown in Table 2. Based on Case 2, the inspection rails are moved toward the girder center at a distance $\mathscr{L}=20 \mathrm{~mm}$ and is then labeled as Case 3. Case 4 refers to the rough girder surface, due to physical and chemical damage during the long-term operation of the 


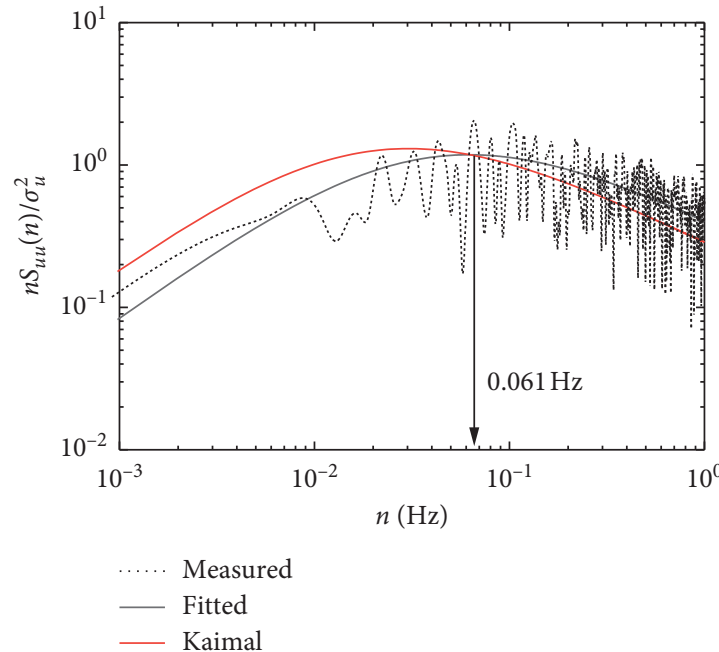

(a)

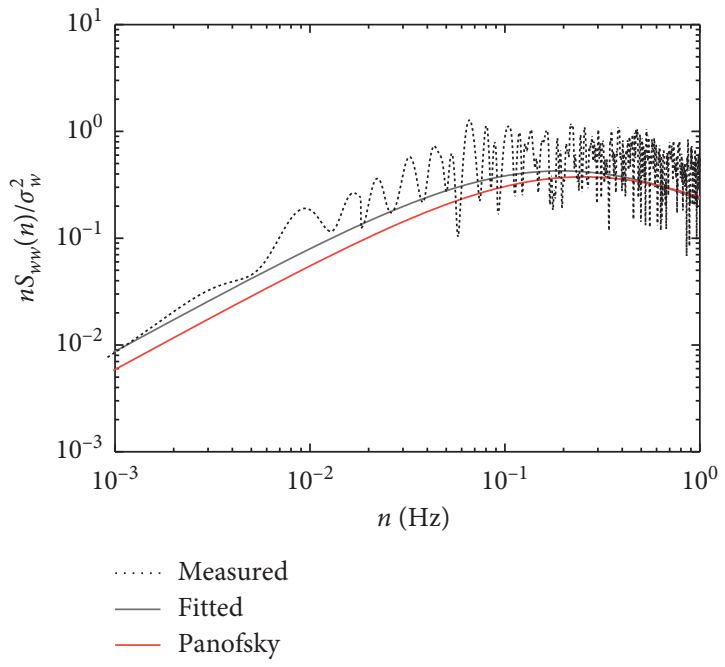

(b)

Figure 4: Comparisons of measured and recommended turbulence power spectra at the girder height: (a) longitudinal component; (b) vertical component.

TABLE 1: Descriptions of testing cases, at 1/60 scaling ratio.

\begin{tabular}{|c|c|c|c|c|}
\hline No. & Pedestrian guardrail & $\mathscr{L}(\mathrm{mm})>$ & $\mathscr{R}(\mathrm{mm})$ & Sketch \\
\hline
\end{tabular}

Case $0 \quad$ Without any subsidiary structures

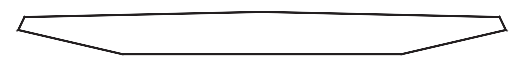

2

Case 1

Case 2

Case 3

II

II

0

20

0
0

0

0

1.28

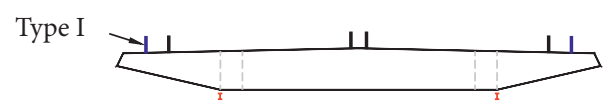

Type II

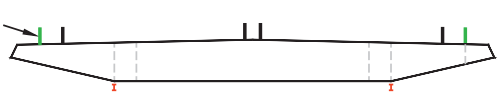

Type II

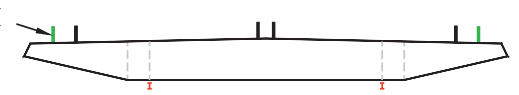

Type I

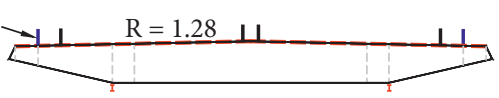

real bridge. The sandpapers are pasted on the model surface of Case 1 to simulate the roughness at the corresponding scaling ratios. The roughness level at $1 / 60$ scaling ratio is $\mathscr{R}=1.28 \mathrm{~mm}$, while that at $1 / 300$ scaling ratio is $\mathscr{R}=0.26 \mathrm{~mm}$.
3.2. Experimental Testing of Aerostatic Forces. Static forces are due to the averaged wind speed acting on the bridge at an equilibrium state. Figure 5 shows the lift force, drag force, and pitching moment acting on the girder per unit span length, which are calculated by 
TABLE 2: Details of the pedestrian guardrails tested, in $1 / 60$ scaling ratio $(\mathrm{cm})$.

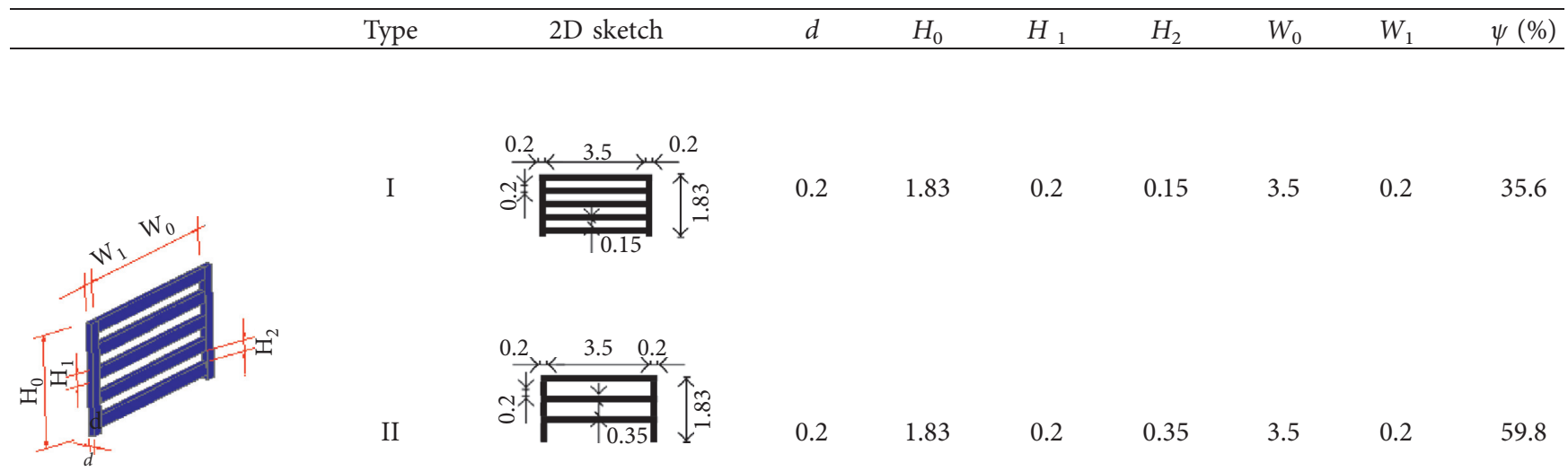

$$
\left\{\begin{array}{l}
F_{L}=\frac{1}{2} \rho U^{2} \mathrm{BC}_{L}(\alpha) \\
F_{D}=\frac{1}{2} \rho U^{2} \mathrm{DC}_{D}(\alpha) \\
M_{Z}=\frac{1}{2} \rho U^{2} B^{2} C_{M}(\alpha)
\end{array}\right.
$$

where $F_{L}, F_{D}$, and $M_{Z}$ are the aerostatic lift force, drag force, and pitching moment; $U$ is the mean wind speed; $\rho$ is the air density; $B$ and $D$ are the width and height of the model; $C_{L}$, $C_{D}$, and $C_{M}$ are the coefficients corresponding to the three components of aerostatic forces (AFC); and $\alpha$ is the AoA.

The AFCs are essential parameters needed in the following analysis to identify AAF and to calculate buffeting responses. The experimental tests of AFCs are conducted in an industrial wind tunnel of Southwest Jiaotong University (XNJD-1); the tested cases are described in Section 3.1 and listed in Table 1 . The dimension of the testing section is $2.4 \mathrm{~m} \times 2.0 \mathrm{~m} \times 16.0 \mathrm{~m}$ (width $\times$ height $\times$ length), with the wind speed being adjustable from $1 \mathrm{~m} / \mathrm{s}$ to $45 \mathrm{~m} / \mathrm{s}$ (turbulent intensity $<0.5 \%)$. The section models, with the scaling ratio $1 / 60$, are placed in the middle of the testing section and span all the section width. The incoming wind is measured one chord upwind from the leading edge of the model using a four-hole probe. Aerostatic forces are measured at both ends of the model using a 3-DOF balance system mounted outside the wind tunnel. The AFCs are then calculated based on (3). The AoA is simulated by pitching the model to make it inclined against the mean wind direction. For each case, the AFCs are tested at a total of 25 AoAs ranging from $-12^{\circ}$ to $+12^{\circ}$. The variations of AFCs with AoA are shown and discussed in Supplementary B.

Then, the aerostatic forces acting on the main girder can be obtained by substituting the design mean wind speed as $U=42.61 \mathrm{~m} / \mathrm{s}$ into (3). For the towers, piers, and cables, the mean wind speeds can be obtained according to (1), considering the variation with height.

3.3. Experimental Testing of AAF. In the present study, the testing of AAF is based on the traditional buffeting theories of Davenport [8] and Scanlan [30]. Of particular interest is the square of the module of the AAF $|\chi(\omega)|^{2}$, which can be obtained in the frequency domain by considering the power spectra of the fluctuating wind and aerodynamic forces. Conventionally, the experimentally tested AAF is based on an equivalent assumption [18, 31-35] that the admittance of a buffeting force due to the longitudinal turbulence $(u)$ equals that due to the vertical turbulence $(w)$. Then, the buffeting forces are given by

$$
\left\{\begin{array}{l}
S_{L}(\omega)=(\rho U B)^{2}\left[C_{L}^{2}(\alpha) S_{u}(\omega)\left|\chi_{L}(\omega)\right|^{2}+\frac{1}{4}\left[C_{L}^{\prime}(\alpha)+C_{D}(\alpha)\right]^{2} S_{w}(\omega)\left|\chi_{L}(\omega)\right|^{2}\right] \\
S_{D}(\omega)=(\rho U B)^{2}\left[C_{D}^{2}(\alpha) S_{u}(\omega)\left|\chi_{D}(\omega)\right|^{2}+\frac{1}{4} C_{D}^{\prime 2}(\alpha) S_{w}(\omega)\left|\chi_{D}(\omega)\right|^{2}\right] \\
S_{M}(\omega)=(\rho U)^{2} B^{4}\left[C_{M}^{2}(\alpha) S_{u}(\omega)\left|\chi_{M}(\omega)\right|^{2}+\frac{1}{4} C_{M}^{\prime 2}(\alpha) S_{w}(\omega)\left|\chi_{M}(\omega)\right|^{2}\right]
\end{array}\right.
$$




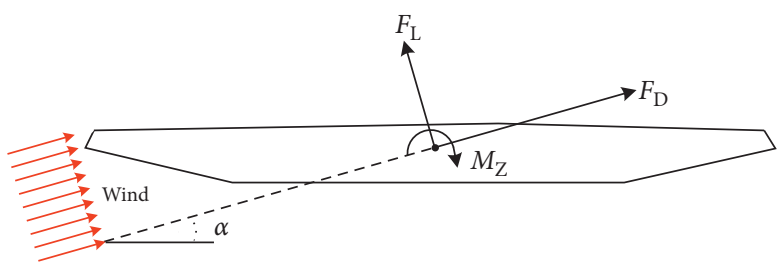

Figure 5: Aerostatic forces acting on the girder per unit span length.

where $S_{L}(\omega), S_{D}(\omega)$, and $S_{M}(\omega)$ are the spectra of the lift force, drag force, and pitching moment, respectively. $S_{u}(\omega)$ and $S_{w}(\omega)$ are the spectra of the longitudinal and transverse turbulence. $\left|\chi_{D}\right|^{2},\left|\chi_{L}\right|^{2}$, and $\left|\chi_{M}\right|^{2}$ are the equivalent AAFs of buffeting drag, lift, and moment forces.

The wind tunnel tests are also carried out in XNJD-1. The fluctuating wind field is generated by the grid installed upstream from the model. Anemometer cobra probes are used to measure the time histories of fluctuating wind, as shown in Figure 6(a), which resolves the instantaneous vertical and longitudinal components. The intensity and integral scale of the generated turbulence field are listed in Table 3. The testing cases and the girder configurations are the same as those in the aerostatic testes in Section 3.2. The scaling ratios of the models are 1/300. Each model includes a testing section $(L=300 \mathrm{~mm})$ and a compensation section ( $L=400 \mathrm{~mm}$ ). The testing section is fixed on the high-frequency force balance (HFFB) to measure the time histories of buffeting forces, as shown in Figure 6(b). The AAF of each case is conducted at different AoAs $\left(0^{\circ}, \pm 3^{\circ}, \pm 5^{\circ}\right)$. Then the time histories of fluctuating wind and buffeting forces are spectrally analyzed in frequency domain, and the AAF can be determined according to (4).

The experimental results of AAF of all cases are shown and discussed in Supplementary C; here Case 1 at AoA $0^{\circ}$ is shown in Figure 7 as a typical example. For comparison with the Sears function, the frequency is normalized as a reduced form $\kappa=\omega \mathrm{B} / \mathrm{U}$. As shown in the figure, the tested $\left|\chi_{D}\right|^{2},\left|\chi_{L}\right|^{2}$, and $\left|\chi_{M}\right|^{2}$ are smaller than the Sears function overall frequency range, especially at high frequencies. Therefore, the errors caused by the empirical simplification Sears function in calculating buffeting responses should be evaluated, which will be presented in Section 4.3.1.

3.4. Wind Field Simulation. To obtain the buffeting forces acting on the entire bridge, the fluctuating wind field at various structures on the bridge should be obtained firstly. Due to the structural and budget limitations, the field measurements are usually conducted at several typical positions at the bridge site, e.g., $[7,36,37]$. Therefore, the wind field of the entire bridge should be obtained based on the limited measuring data [3]. To enhance the computational efficiency, the fluctuating wind inputs are exerted on the uniformly distributed locations, as shown in Figure 8. The approach bridges are neglected due to their insignificant contributions to the buffeting responses $[15,38]$. The main girder is divided into 29 simulation points (nos. 1-29) along the span, while the corresponding points on the cables are nos. $30-58$. The towers and piers are simulated by points nos. 59-66.
The longitudinal and vertical fluctuating winds are generated, respectively, by the spectral representation method extended by Deodatis [3]. The wind speeds at the 66 points are considered as ergodic stochastic processes and simulated as a set of correlated time series:

$$
f_{j}(t)=2 \sum_{m=1}^{j} \sum_{l=1}^{N}\left|H_{\mathrm{jm}}\left(\omega_{\mathrm{ml}}\right)\right| \sqrt{\Delta \omega} \cos \left[\omega_{\mathrm{ml}} t-\theta_{\mathrm{jm}}\left(\omega_{\mathrm{ml}}\right)+\varphi_{\mathrm{ml}}\right] \text {, }
$$

where $\omega_{\mathrm{ml}}=((1-1)+m / N) \Delta \omega$ is the double-indexing frequency; $\Delta \omega=\omega_{u} / N$ is the frequency interval, with the cut-off frequency $\omega_{u}=10 \pi \mathrm{rad} / \mathrm{s}$, and $N=1024$ is the number of frequency intervals. $\varphi_{\mathrm{ml}}$ is a random phase angle uniformly distributed in $[0,2 \pi] . H_{j m}\left(\omega_{m l}\right)$ is the $(j, m)$ th element of the matrix $H(\omega)$, and $\theta_{j m}$ is the corresponding phase. The matrix $H(\omega)$ is obtained by the Cholesky decomposing of the target matrix $S(\omega)$ :

$$
S(\omega)=H(\omega) H^{T *}(\omega)
$$

To consider the spatial distributions of fluctuating wind along various parts of the bridge, the matrix $S(\omega)$ is arranged in the cross-spectral form:

$$
S_{j m}(\omega)=\sqrt{S_{j}(\omega) S_{m}(\omega)} \operatorname{Coh}(\omega, r),
$$

where $S_{j}(\omega)$ and $S_{m}(\omega)$ are the target spectra at points $j$ and $m$, respectively, Coh $(\omega, r)$ is the spatial coherence function, and $r$ is the distance between the two points. The Davenport coherence function [6] is utilized in this study, and the coherence coefficient is taken as 7 .

The simulations are conducted in Matlab R2012a program, with the time interval $\Delta t=0.125 s$ and the sampled duration $T=600 \mathrm{~s}$. Figure 9 shows the equivalent fluctuating wind speeds at the midspan (point 15), and the simulated power spectra are given in Figure 10. The simulated power spectra conform well to the target ones in both directions, which validates the effectiveness and reliability of the wind field simulation.

3.5. Buffeting Forces. It should be noted that the AAF is frequency dependent and therefore cannot be directly utilized in the buffeting forces time domain. To solve this problem, the equivalent spectrum is utilized as the target power spectrum in (6). The equivalent spectrum is taken as the measured wind spectrum multiplied mathematically by the experimental AAF, for example, $S_{u}(\omega)\left|\chi_{L}(\omega)\right|^{2}$. Then, the buffeting forces acting on the bridge can be deduced from (4). In this case, the effect of 


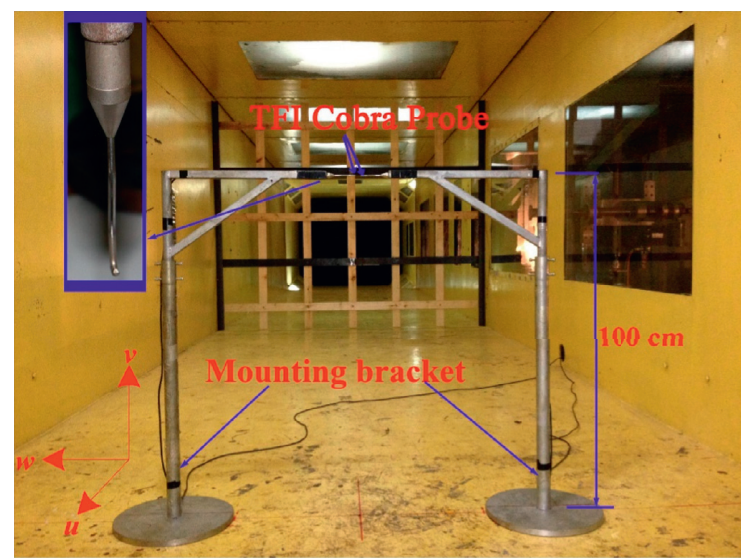

(a)

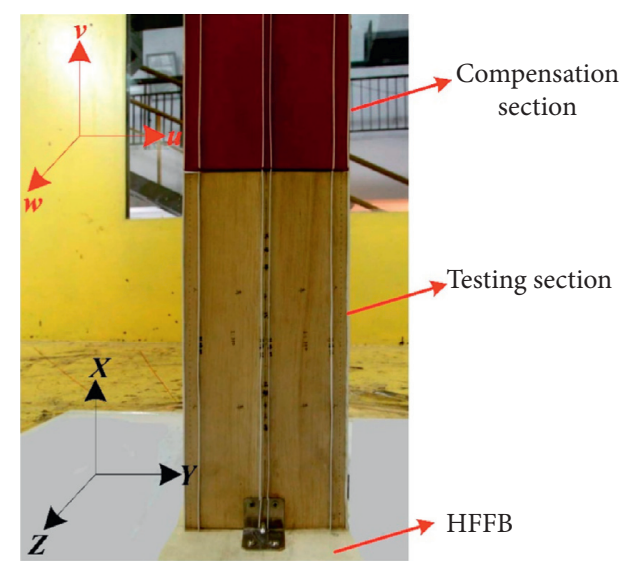

(b)

Figure 6: Testing of AAF in the wind tunnel: (a) measuring fluctuating wind speed; (b) the testing model. The directions $u, v$, and $w$ correspond to the $y, x$, and $z$ axes on the bridge, respectively.

TABLE 3: Turbulence characteristics generated in the wind tunnel.

\begin{tabular}{lccccc}
\hline \multicolumn{2}{c}{ Turbulent integral scales $(\mathrm{m})$} & \multicolumn{3}{c}{ Turbulent intensities (\%) } \\
\hline$L_{u}$ & $L_{v}$ & $L_{w}$ & $I_{u}$ & $I_{v}$ & $I_{w}$ \\
0.107 & 0.042 & 0.054 & 7.19 & 6.12 & 5.67 \\
\hline
\end{tabular}

AAF can be naturally included. Figure 11 shows the simulated buffeting forces at the girder midspan (point $15)$ of Case 1 as a typical example. The AFCs $C_{L}, C_{D}, C_{M}$ and the derivatives $\mathrm{C}_{L}^{\prime}, \mathrm{C}^{\prime}{ }_{D}, \mathrm{C}^{\prime}{ }_{M}$ have been determined in Section 3.2. The mean wind speed $U$ at each point is determined in Section 2.3.

\section{Buffeting Analysis of the Bridge}

4.1. Time-Domain Analysis. The buffeting analysis is performed in ANSYS 15.0 based on a three-dimensional finite element (FE) model of the bridge. The details of the FE model can be found in our previous study [39], which will not be repeated here for the sake of brevity. The modeling of the aerodynamic forces due to fluctuating wind components is expressed in terms of aerostatic forces and buffeting forces [40], which have been obtained in Section 3.2 and Section 3.5, respectively. The buffeting analysis is conducted by a full method of transient dynamics. During the analysis, the Rayleigh damping matrix is utilized [41] and the damping ratios of the selected two modes ( $L-S-1$ and $T-S-1$ where $L$ is the lateral vibration, $T$ is the torsional vibration, and $S$ is the symmetry), which are used to determine the proportionality constants, are both assumed to be $0.5 \%$ [6]. It should be noted that the frequencies of $L-S-1$ and $T-S-1$ are $0.1122 \mathrm{~Hz}$ and $0.3887 \mathrm{~Hz}$, respectively. The sampled duration is $600 \mathrm{~s}$.

4.2. Buffeting Responses of the Original Final Design. All the following analyses are conducted at the design reference speed. To present the basic feature of the buffeting response of the CUN-TAN Yangtze Bridge; the results of the original final design (Case 1 ) at $0^{\circ} \mathrm{AoA}$ are presented as a typical sample.
To refine the analysis, the analysis is based on measured power spectra of fluctuating wind, experimental tested AFC, and AAF. The vertical, lateral, and torsional buffeting displacements at the midspan (point 15) are presented as shown in Figure 12 in time domain. The corresponding power spectra are shown in Figure 13, which reveals the contribution of different frequencies to the overall buffeting response. It can be concluded that the predominant frequencies of vertical buffeting displacement $\left(\delta_{V}\right)$ correspond to the $V-A-1, V-S-1$, and $V-S-2$ modes, while the predominant frequency of lateral displacement $\left(\delta_{L}\right)$ is mainly composed of the $L-S-1$ mode. As shown in Figure 13(c), the frequency-domain torsional displacement $\left(\delta_{T}\right)$ has several higher peaks, which implies that the torsional vibration of the main girder can result from the synthetic impacts of the $L-S-1$ and $T-S-1$ modes.

The root-mean-square (RMS) of the vertical, lateral, and torsional buffeting displacements $\left(\delta_{V}^{\prime}, \delta_{L}^{\prime}\right.$, and $\left.\delta_{T}^{\prime}\right)$ of Case 1 is shown in Figure 14. It is shown that $\delta_{V}^{\prime}, \delta_{L}^{\prime}$, and $\delta_{T}^{\prime}$ are all symmetrical about the midspan. The lateral and torsional displacements $\delta_{L}^{\prime}$ and $\delta_{T}^{\prime}$ are the most prominent at the midspan, while the maximum of $\delta^{\prime}{ }_{V}$ shows a leaning trend to the $1 / 4$ span. The primary reason could be related to the mode shapes of the bridge. As shown in Figure 13, the vertical displacement is affected by the $V-A-1, V-S-1$, and $V-S-2$ modes, which involve half or one wave along the span and, synthetically, the maximum occurs near the $1 / 4$ span $[42,43]$. On the other hand, the lateral displacement is mainly controlled by the first-order symmetric lateral vibration $(L-S-1)$, which is typically characterized by half wave along the span and reaches the maximum at the midspan $[42,43]$. As discussed above, the torsional vibration results from the synthetic impacts of the bending modes $L-S-1$ and $T-S-1$, which are both symmetric. Therefore, the maximum of $\delta_{T}^{\prime}$ occurs at the midspan.

\subsection{Effects of Major Aerodynamic Parameters}

4.3.1. Aerodynamic Admittance Function. According to Section 3.3, the aerodynamic admittance function (AAF) is 


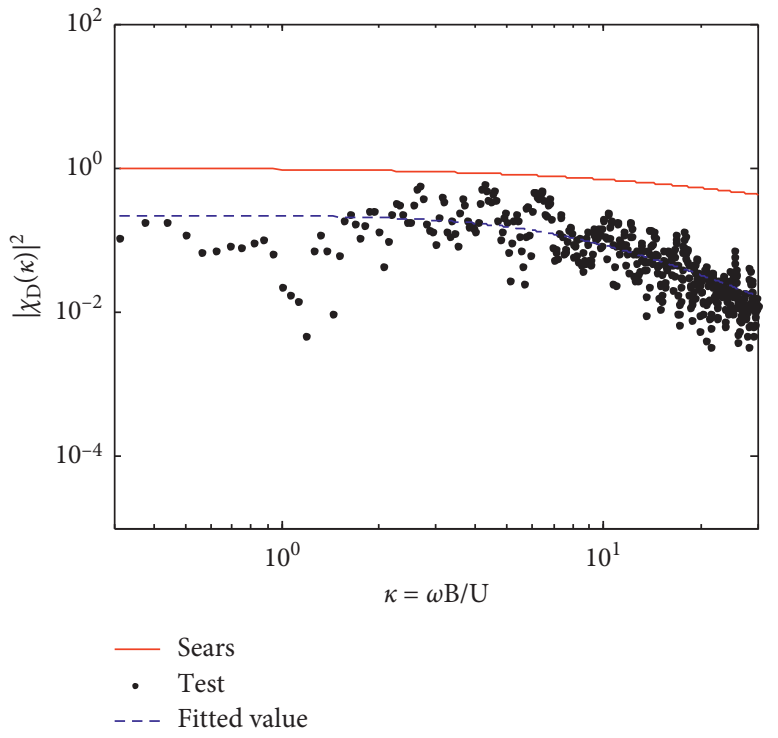

(a)

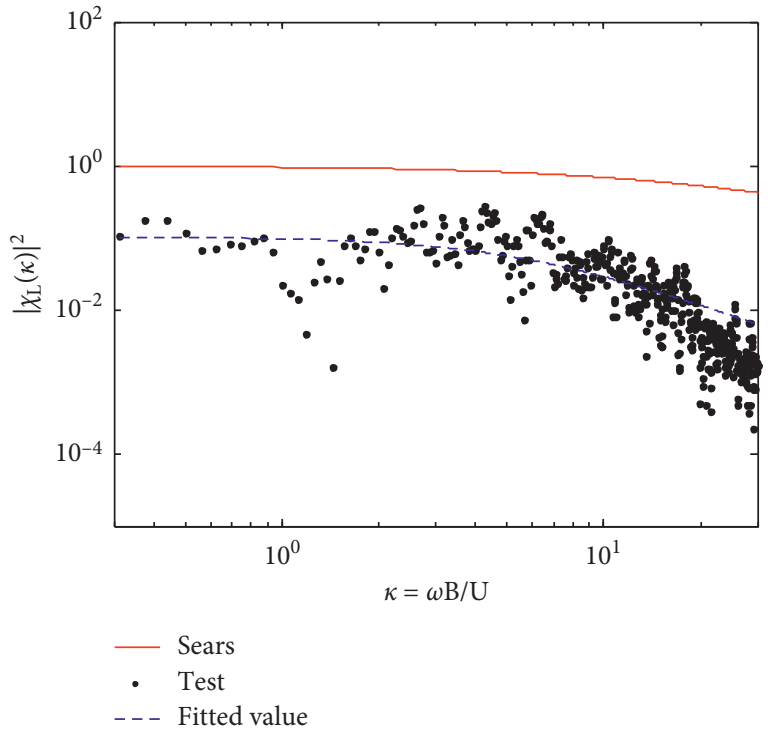

(b)

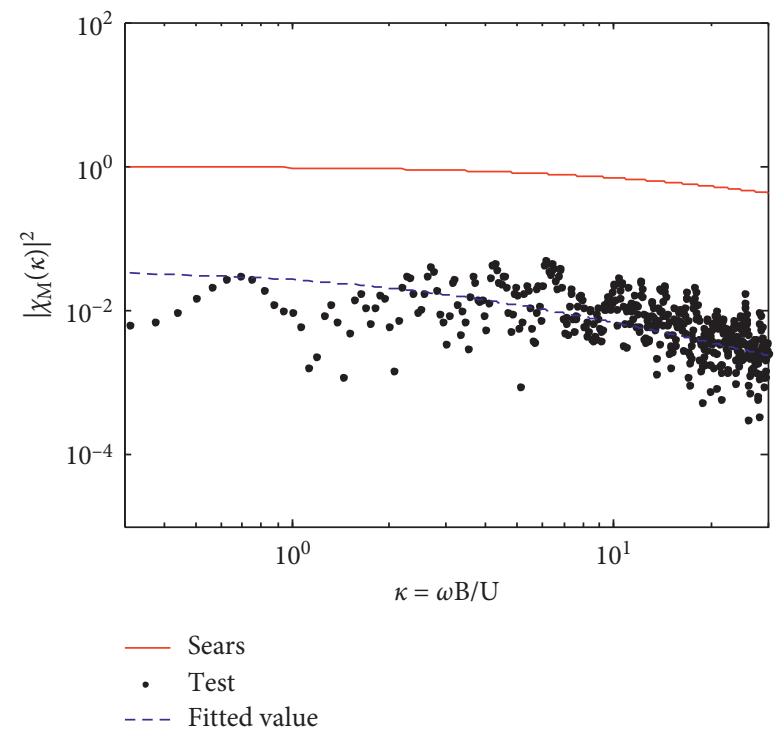

(c)

FiguRE 7: Experimentally tested aerodynamic admittance functions (AAFs) of Case 1 at the angle of attack (AoA) $0^{\circ}$ : (a) $\left|\chi_{D}\right|^{2}$, (b) $\left|\chi_{L}\right|^{2}$, and (c) $\left|\chi_{M}\right|^{2}$.

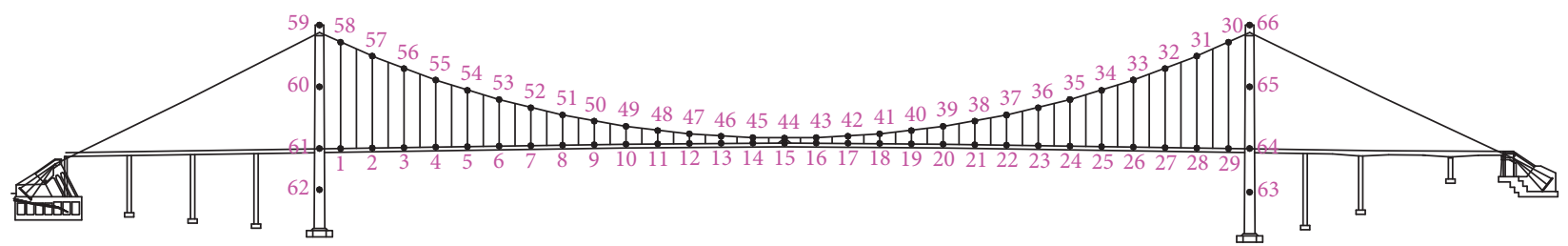

FIgURE 8: The layout of wind field simulation points on the bridge.

of vital importance in buffeting analysis as it improves the conventional buffeting model and considers the unsteady features. In most of the previous studies [14-16], the AAF is usually taken as 1 or empirically utilized the Sears function.
As shown in Figure 7, as the experimentally tested AAF is significantly different from the Sears function, the above simplifications can lead to inaccurate results. Due to the lack of time-domain expressions of AAF, the comparisons 


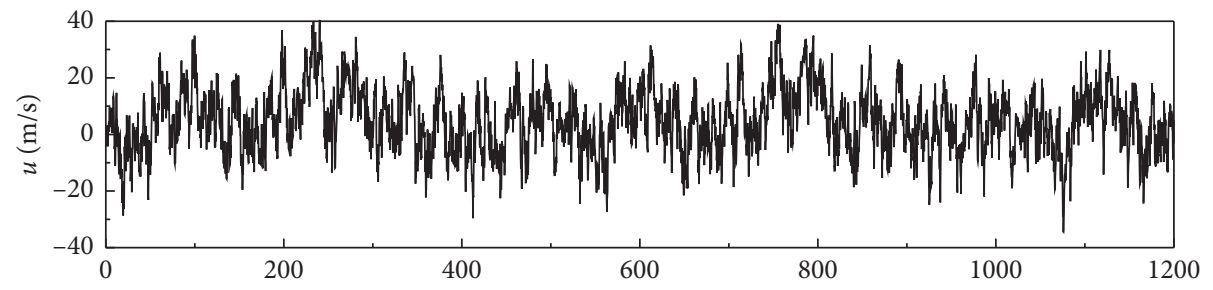

(a)

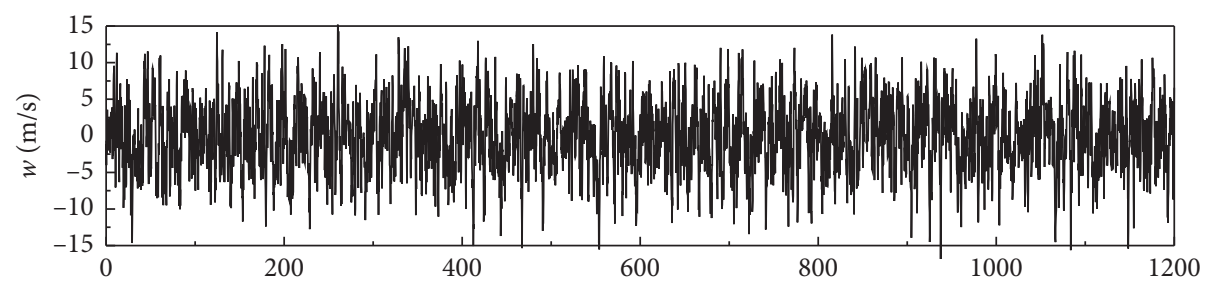

(b)

Figure 9: Time history of the simulated fluctuating wind at the midspan (\#15) of Case 1: (a) longitudinal component; (b) vertical component.

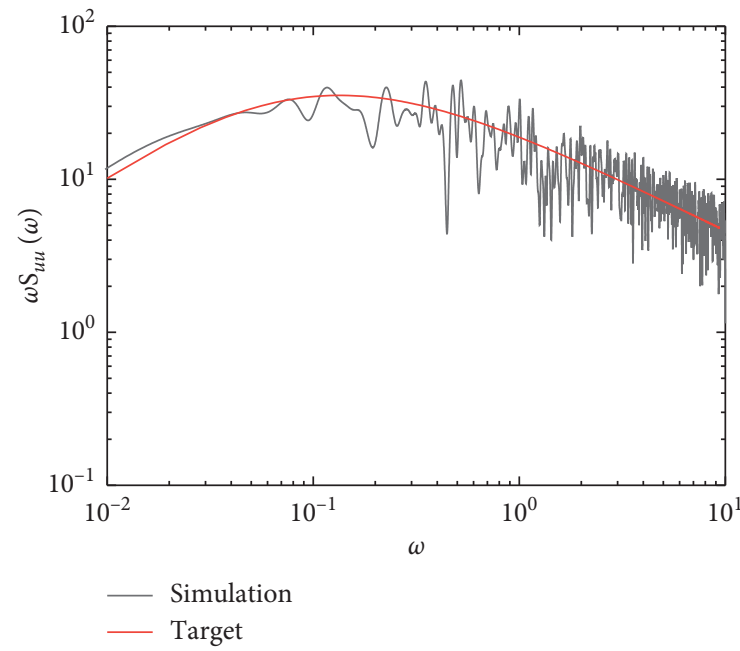

(a)

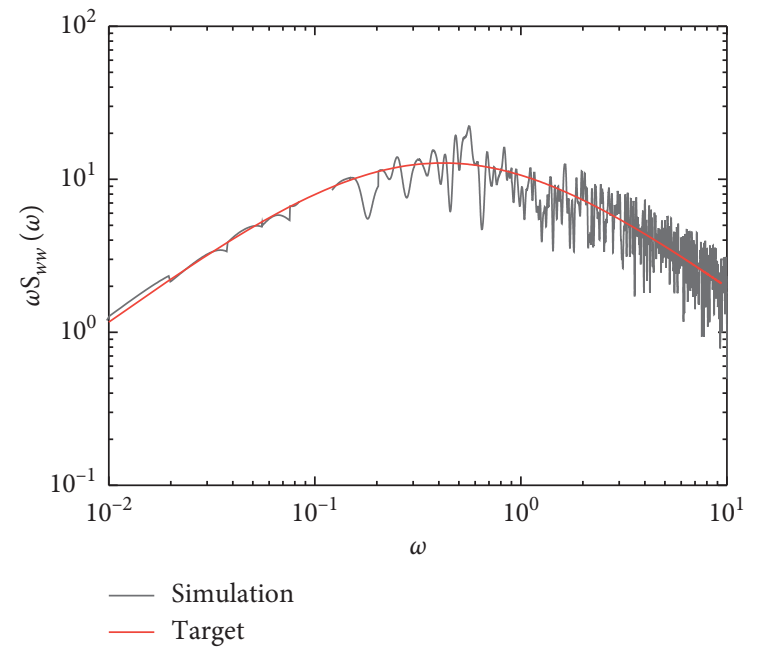

(b)

Figure 10: Comparisons between simulated spectra and target ones at the midspan (\#15) of Case 1: (a) longitudinal component; (b) vertical component. $\mathrm{AoA}=0^{\circ}$.

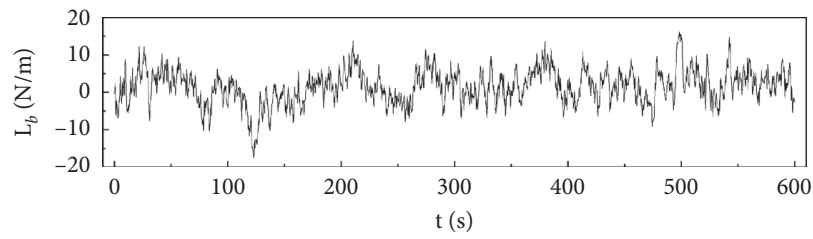

(a)

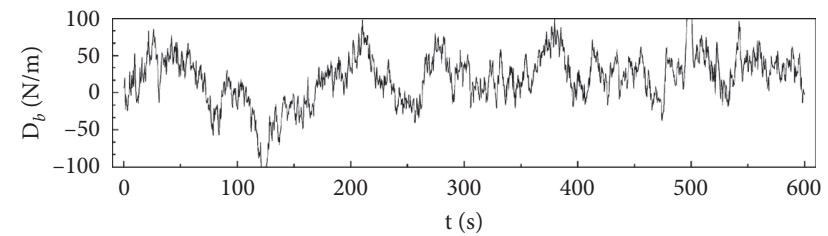

(b)

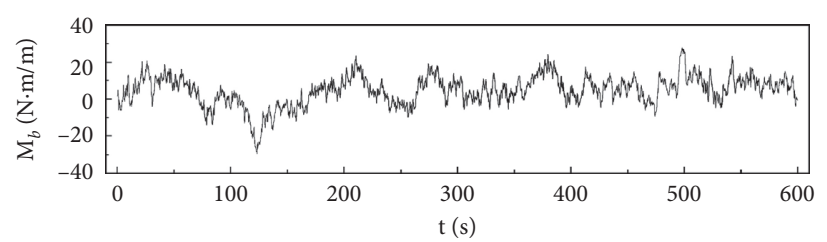

(c)

FIgURE 11: The simulated time histories of buffeting forces at the midspan (\#15) of Case 1 at AoA of $0^{\circ}$ : (a) buffeting lift force; (b) buffeting drag force; (c) buffeting pitching moment. 


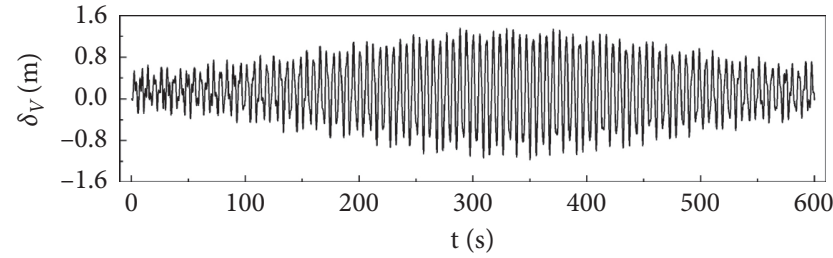

(a)

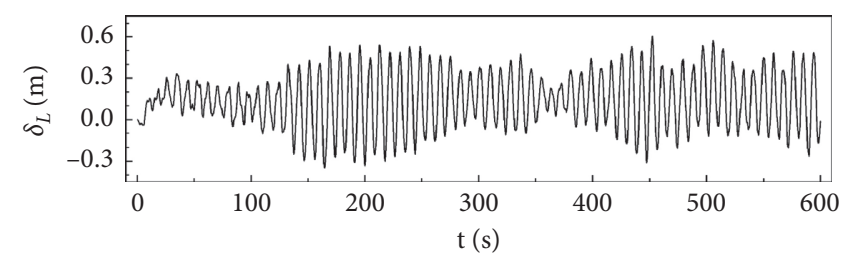

(b)

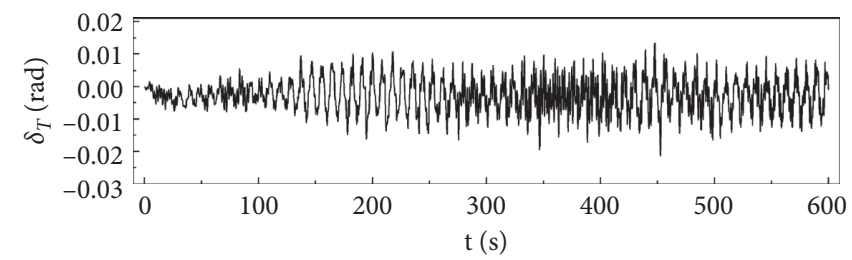

(c)

Figure 12: Time histories of the (a) vertical, (b) lateral, and (c) torsional buffeting displacements at the midspan (\#15) of Case 1 . AoA $=0^{\circ}$.

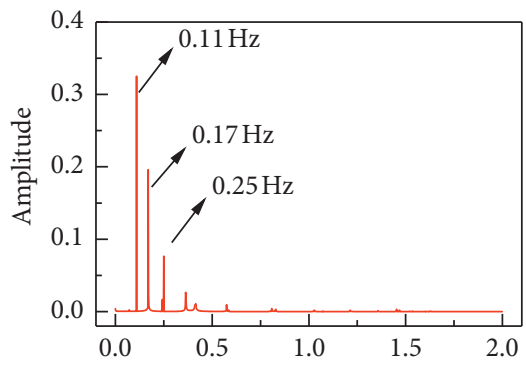

(a)

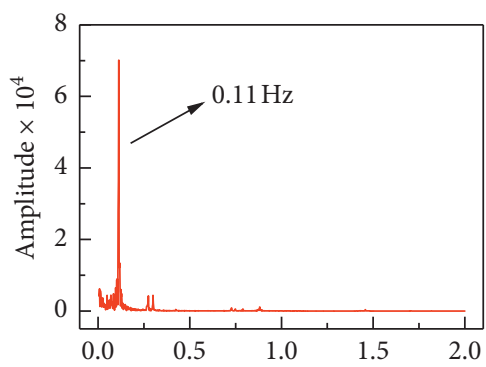

(b)

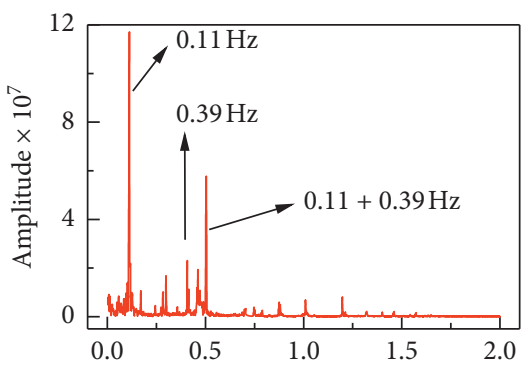

(c)

Figure 13: Power spectra of the (a) vertical, (b) lateral, and (c) torsional buffeting displacements at the midspan (\#15) of Case 1 . AoA $=0^{\circ}$.

between the buffeting responses from simplified and experimental tested AAFs have not been conducted in time domain in the previous studies.

In the present study, the experimental tested $\mathrm{AAF}$ is included in the time domain by taking the target power spectrum in (6) by mathematically multiplying the measured turbulence power spectrum in (3) and the experimental AAF. Therefore, the inaccurate deviations of the buffeting responses caused by the simplified AAFs can be evaluated in time domain. In this regard, the results from the aforementioned three cases are included in the comparisons: the AAF taken as 1 , the Sears function, and the experimentally measured AAF in Section 3.3. The buffeting responses of Case 1 at AoA $=0^{\circ}$ are analyzed based on the three cases, respectively. During the analysis, the rest parameters are kept unchanged.

Figure 15 shows the RMS buffeting displacements of the main girder versus different AAFs. The vertical, lateral, and torsional buffeting displacements $\left(\delta^{\prime}{ }_{V}, \delta_{L}^{\prime}{ }_{L}\right.$, and $\left.\delta_{T}^{\prime}\right)$ obtained when AAF is taken as 1 are the largest among the three cases, while those from Sears function are smaller than those from $\mathrm{AAF}=1$ but larger than those from experimentally tested AAF. Compared with the results from experimentally tested $\mathrm{AAF}$, those from $\mathrm{AAF}=1$ are $20.5 \%, 63.4 \%$, and $25.1 \%$ overestimated at the midspan. The primary reason is that the unsteady effects of the buffeting forces are neglected. The overestimations caused by Sears function at the midspan are $9.0 \%, 23.1 \%$, and $10.1 \%$ for $\delta_{V}^{\prime}, \delta_{L}^{\prime}$, and $\delta_{T}^{\prime}$, respectively. The above overestimations can be also explained by the comparisons in Figure 7, as the Sears function is larger than the three components of experimentally tested AAF over the whole frequency range.

Due to the massive inaccurate deviations caused by the Sears function or without considering the AAF, the actual AAF tested in the wind tunnel are more appropriate for refined buffeting analysis, which can reduce the overall budget of the structure from an economic point of view.

4.3.2. Turbulence Power Spectrum Model. The modeling of the cross-spectral density matrix, i.e., the power spectrum of fluctuating wind, is another key parameter in simulating the wind field on the bridge. Hence, the selection of the power spectrum will significantly affect the accuracy of the wind field simulation results. Due to the difficulties in conducting comprehensive field measurements at the bridge site, most existing researches simulated the fluctuating wind field through empirical power spectrum models. Reference [6] recommends the Kaimal spectrum and Panofsky spectrum to simulate longitudinal and vertical fluctuating wind, respectively. However, the recommended spectra cannot 


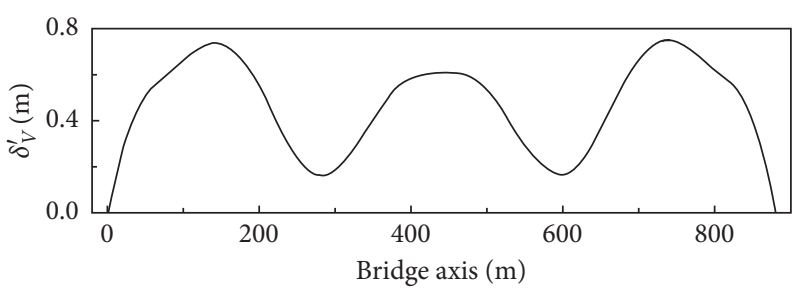

(a)

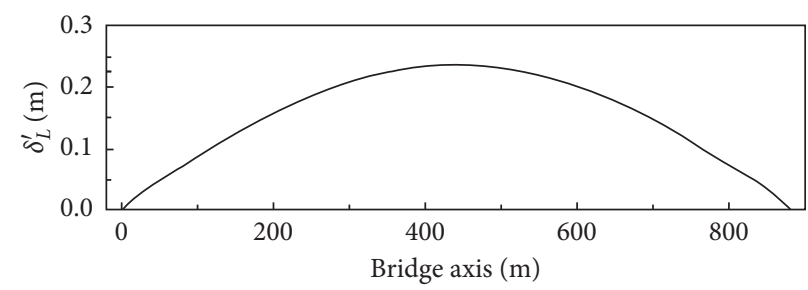

(b)

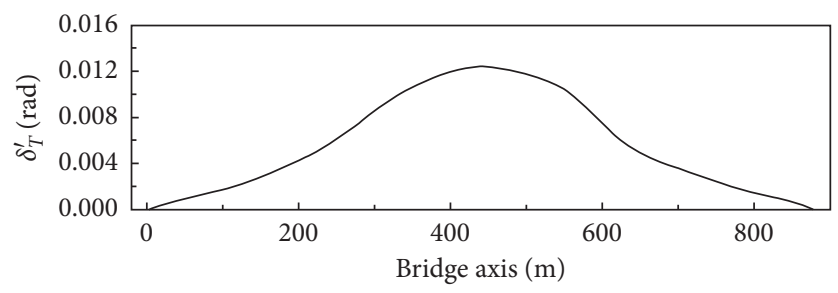

(c)

Figure 14: Root-mean-square (RMS) buffeting displacements of the original design final configuration (Case 1$)$ at AoA of $0^{\circ}:(a)$ vertical displacement $\delta_{V}^{\prime}$; (b) lateral displacement $\delta_{L}^{\prime}$; (c) torsional displacement $\delta_{T}^{\prime}$.

always well satisfy with the complex terrain in different areas, which can lead to inaccurate buffeting responses [36].

CUN-TAN Yangtze Bridge is located in the urban center of a mountainous city in China, and the long-term monitoring of wind field at the bridge site is conducted in the view of refined buffeting analysis. As shown in Figure 4, the measured power spectra of fluctuating wind are significantly different from the recommended models. To study the influences of turbulence power spectrum on the buffeting responses of a long-span bridge in the urban areas, the buffeting analysis of Case 1 at AoA of $0^{\circ}$ is conducted as a typical example. During the analysis, the fluctuating wind field on the bridge is simulated, respectively, based on the recommended and measured turbulence power spectra. Regarding the equivalent target spectrum, the AAF is kept unchanged as the experimentally tested ones in Section 3.3.

The RMS buffeting displacements along the main span versus different turbulence power spectra are shown in Figure 16. The comparisons illustrate that the buffeting responses are underestimated by the recommended spectra. Specifically, the $\delta_{V}^{\prime}, \delta_{L}^{\prime}$, and $\delta_{T}^{\prime}$ at the midspan are $7.34 \%$, $9.44 \%$, and $11.31 \%$ underestimated, respectively. This is mainly because the natural frequencies of the bridge are in the range where the measured spectra are larger than the recommended ones, as shown in Figure 4. In the design stage of the bridge, the undervalued buffeting responses will, in turn, put the structural safety at risk. It is noted that the result of Fenerci and Øiseth [44] is similar to our finding that the buffeting responses are underestimated by the recommended spectra. However, Tao et al. [14] indicate that the buffeting displacements are overestimated by the recommended spectra, which is different from the results in the present study. This is due to the difference of geomorphic features, as the wind characteristics in Tao et al. [14] are measured at a flat terrain site in the lower reach of the Yangtze River. This highlights the necessity of wind field measurements and the measured turbulence power spectra adapted to the terrain features for such a mountainous urban long-span bridge.

4.3.3. Angle of Attack. According to Section 3, the aerostatic and buffeting forces depend on the AoA, and hence the buffeting performance of the bridge will vary with this parameter. However, most researchers [21, 22] mainly concentrated on the results at $\mathrm{AoA}=0^{\circ}$ when conducting buffeting analyses, which means that the aerostatic and buffeting forces are parallel to the girder plane. In Section 2.3, the measured mean wind velocity vector at the bridge site is generally inclined toward the girder plane. To study the influence of AoA on the buffeting responses, the buffeting analysis of Case 1 is conducted at different AoAs. Considering that the measured AoA is mainly in the range $\left(-8^{\circ}-+5^{\circ}\right)$, the cases $0^{\circ}, \pm 3^{\circ}, \pm 5^{\circ} 0^{\circ}, \pm 3^{\circ}, \pm 5^{\circ}$ are included in the comparisons. The AFC and AAF at each AoA have been experimentally tested in Sections 3.2 and 3.3, while the turbulence power spectra are kept unchanged as the measured ones to merely investigate the influence of AoA.

The RMS buffeting displacements on the main girder of Case 1 are shown in Figure 17, which are greatly influenced by AoA. At positive AoAs, the displacements are larger than those at $0^{\circ}$ and the influences of $\mathrm{AoA}=+5^{\circ}$ are more significant than $\mathrm{AoA}=+3^{\circ}$. In particular, at the midspan, the vertical, lateral, and torsional displacements $\left(\delta_{V}^{\prime}, \delta_{L}^{\prime}\right.$, and $\left.\delta_{T}^{\prime}\right)$ increased by $18.1 \%, 34.1 \%$, and $22.2 \%$ when the AoA changes from $0^{\circ}$ to $+5^{\circ}$. If the AoA is changed from $0^{\circ}$ to negative values, the buffeting responses exhibit different changes in the three directions: the $\delta_{V}^{\prime}$ is reduced, the $\delta_{T}^{\prime}$ is increased, and the $\delta_{L}^{\prime}$ is changed a little. At the midspan, the decreases of $\delta_{V}^{\prime}$ are $4.6 \%$ and $6.8 \%$, respectively, at AoA $=-3^{\circ}$ and $-5^{\circ}$, while the corresponding increases of $\delta_{T}^{\prime}$ are $4.67 \%$ and $7.09 \%$, respectively.

For such a mountainous urban bridge, ignoring AoA will put the structural safety at risk. Therefore, the buffeting 


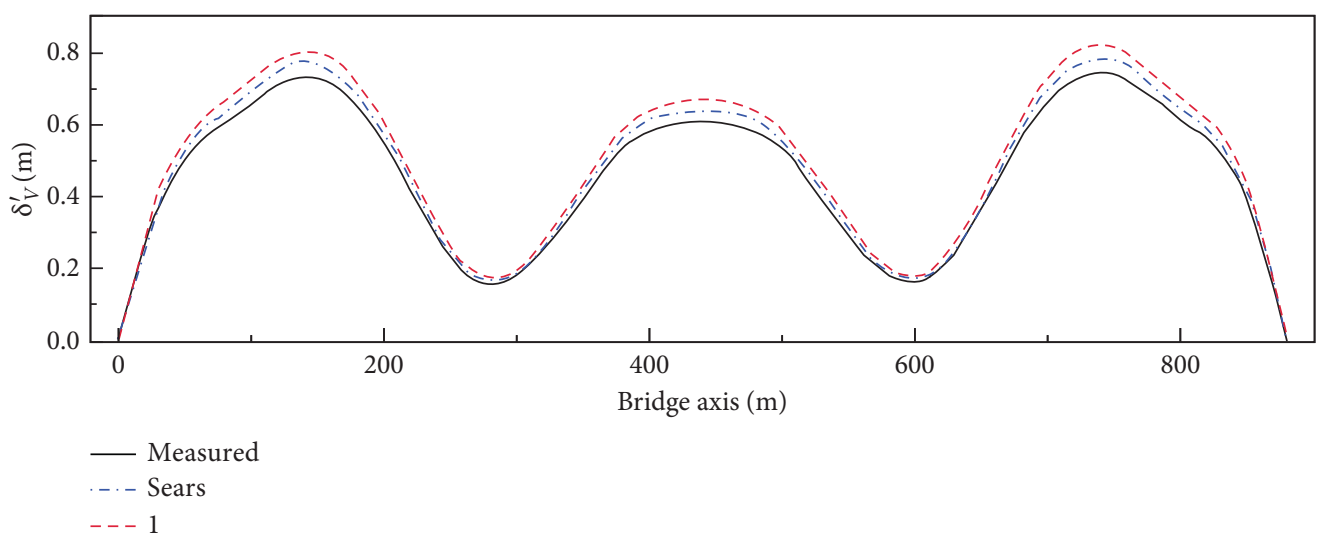

(a)

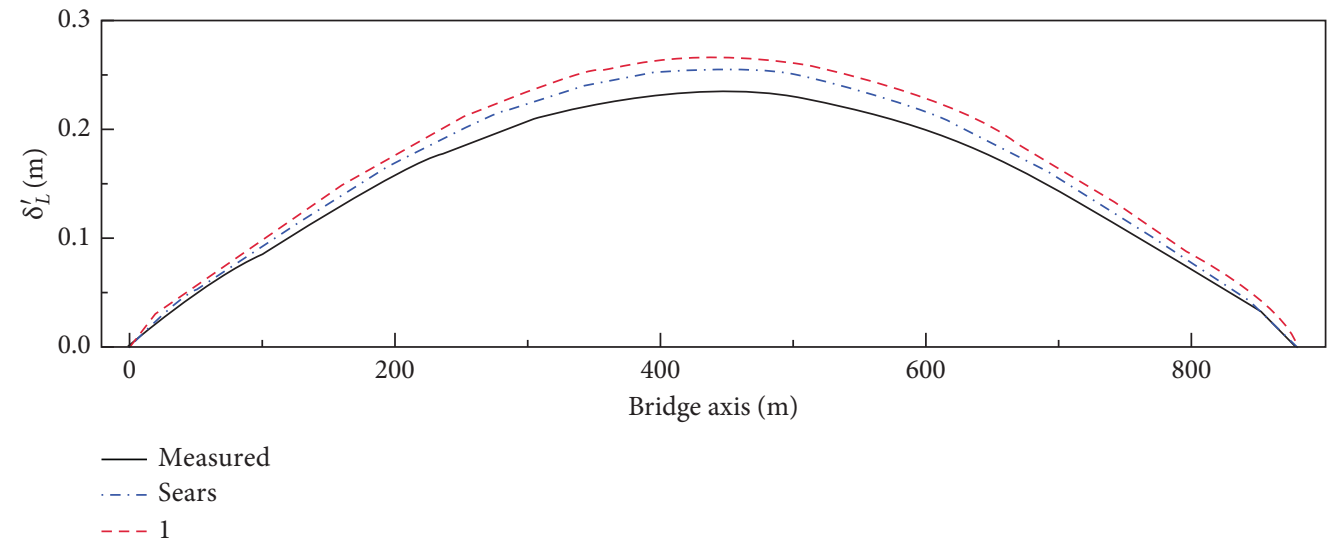

(b)

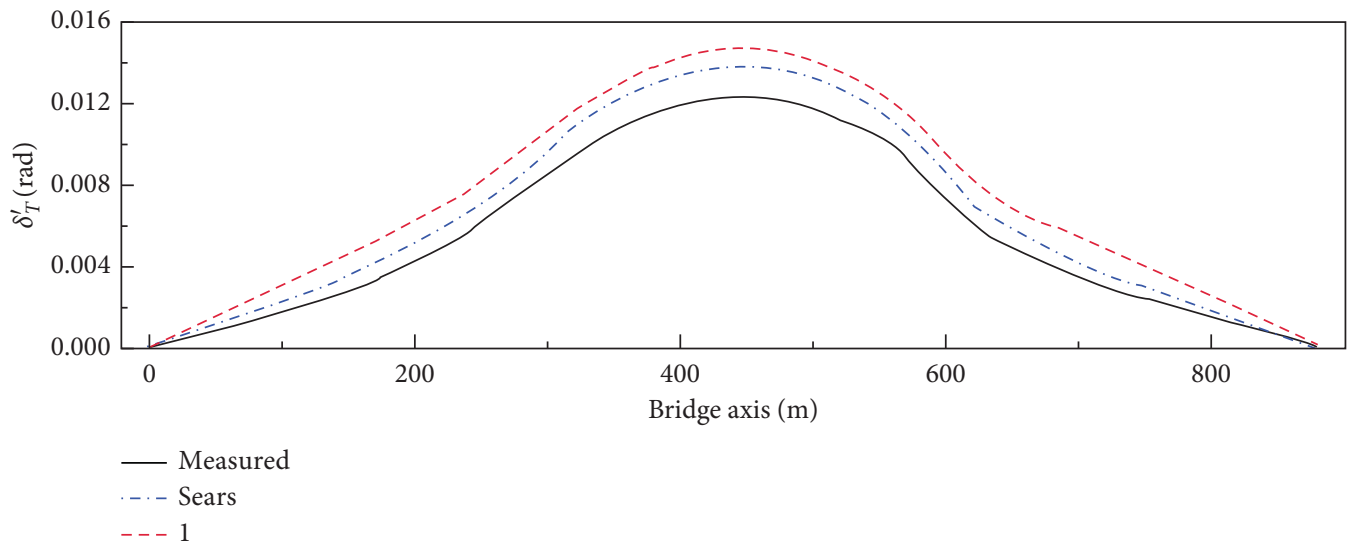

(c)

FIgURE 15: The influences of AAF on the buffeting responses at AoA of $0^{\circ}$ (Case 1): (a) RMS vertical displacement $\delta_{V}^{\prime}$; (b) RMS lateral displacement $\delta_{L}^{\prime}$; (c) RMS torsional displacement $\delta_{T}^{\prime}$.

analysis of such a long-span bridge should be conducted in different AoAs to evaluate the buffeting performance veritably. AoAs included in the analysis should be based on the field-measured data.

4.4. Buffeting Control by Minor Modifications of the Girder. According to existing literature [23, 27], geometrical optimizations of the girder are effective measures in suppressing the wind-induced vibrations on bridges while not significantly increasing the construction budget. This section introduces several minor modifications to the originally designed girder (Case 1) and studies their influences on the buffeting responses of a long-span suspension bridge. The details of each case have been shown in Section 3.1 and will be explained in the subsequent discussions. For each case, respectively, the AFC and AAF have been experimentally tested in Sections 3.2 and 3.3, and then the buffeting responses are calculated and 


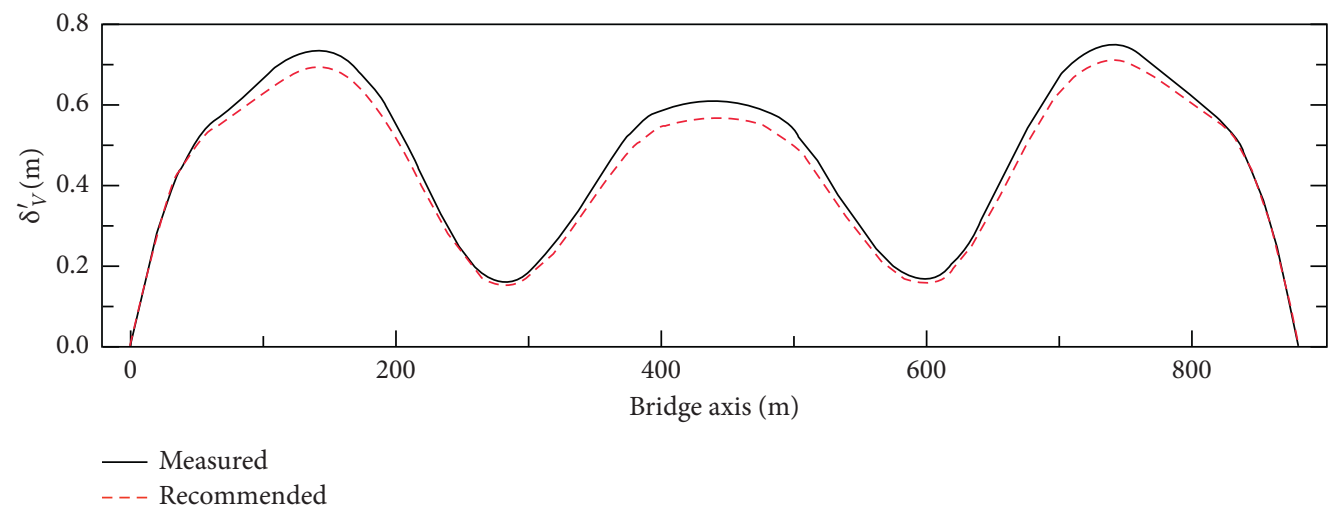

(a)

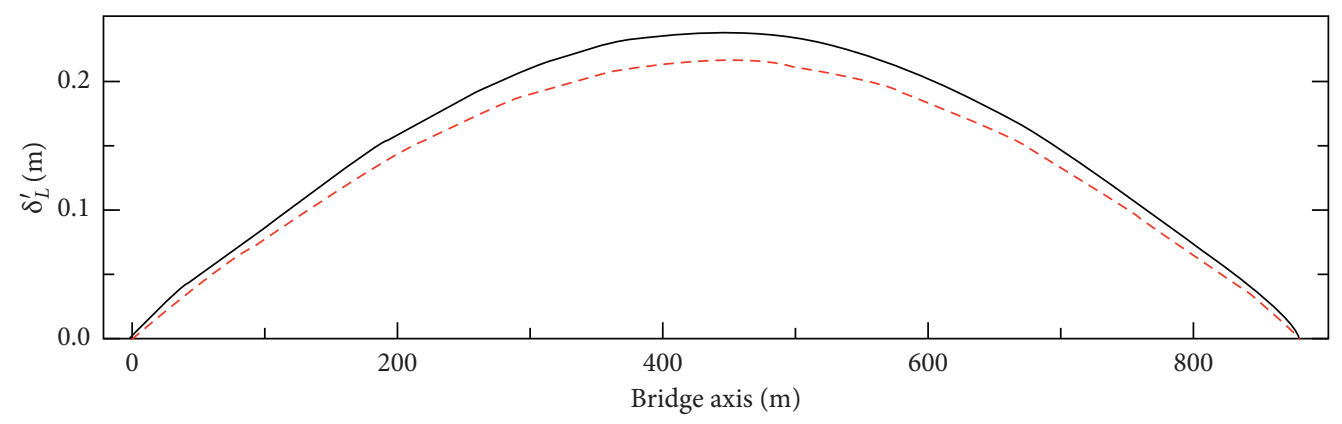

— Measured

- - - Recommended

(b)

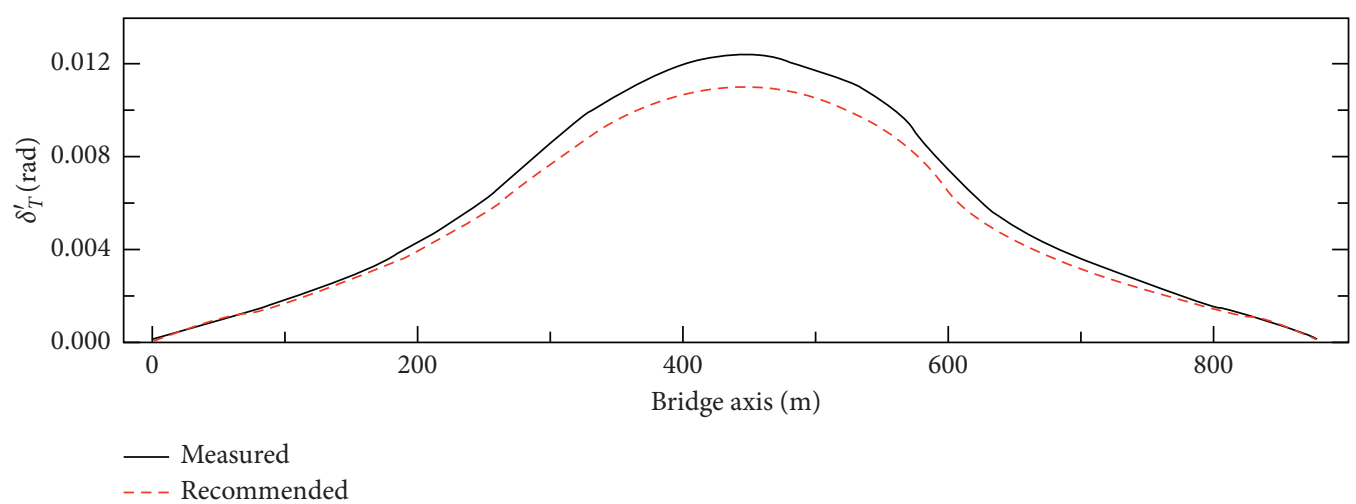

(c)

FIgURE 16: The influences of AAF turbulence power spectra on the buffeting responses at AoA of $0^{\circ}$ (Case 1): (a) RMS vertical displacement $\delta_{V}^{\prime}$; (b) RMS lateral displacement $\delta_{L}^{\prime}$; (c) RMS torsional displacement $\delta_{T}^{\prime}$.

compared at AoA of $0^{\circ}$ and $\pm 5^{\circ}$. During the analyses, the turbulence power spectra are kept unchanged by adopting the field-measured ones in Section 2.3. The RMS buffeting displacements of different cases in the vertical, lateral, and torsional directions are shown in Figures 18-20, respectively.

4.4.1. With and without Subsidiary Structures. The comparisons between those with and without subsidiary structures on the girder are analyzed at first. Compared with those of Case 0 , the vertical, lateral, and torsional displacements $\left(\delta_{V}^{\prime}, \delta_{L}^{\prime}\right.$, and $\left.\delta_{T}^{\prime}\right)$ of Case 1 at the midspan increased by
$12.36 \%, 15.22 \%$, and $17.17 \%$ at AoA of $0^{\circ}$. The influences are more significant at large AoAs, as the increases in the three directions are $12.73 \%, 48.05 \%$, and $36.29 \%$ at AoA of $+5^{\circ}$, while they are $43.21 \%, 14.01 \%$, and $7.80 \%$ at AoA of $-5^{\circ}$, respectively.

Computational Fluid Dynamics (CFD) approaches are conducted to determine how the flow fields are changed by the subsidiary structures that influence the buffeting responses. This can provide insight into fluid mechanisms [40] and guide the structural designs in wind-engineering to a better level [45]. The details of the CFD simulation can be found in a previous work conducted by the author [46], 


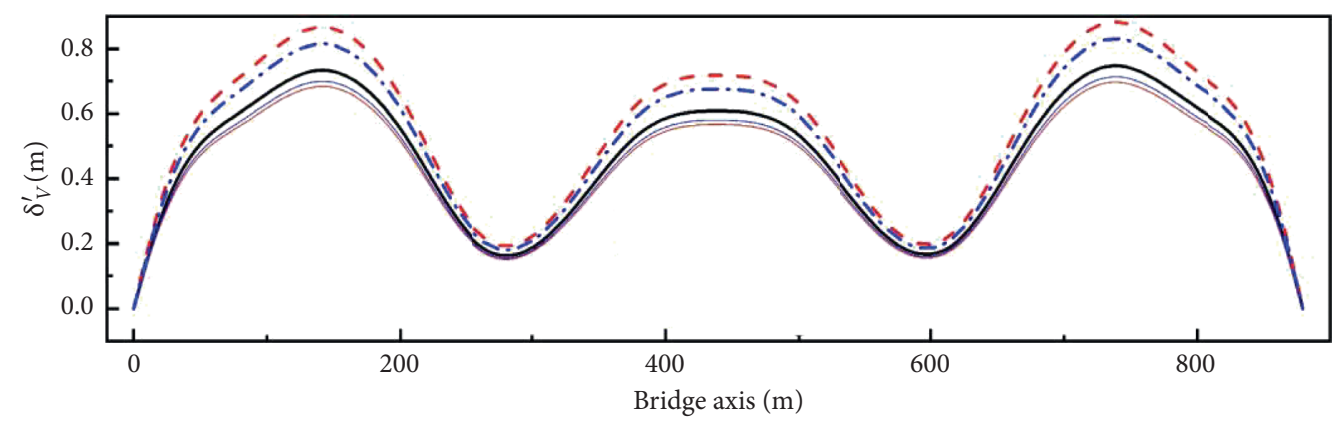

$$
\begin{aligned}
& -\mathrm{AoA}=0^{\circ} \\
& --\mathrm{AoA}=+5^{\circ} \\
& --\mathrm{AoA}=+3^{\circ}
\end{aligned}
$$

$\mathrm{AoA}=-5^{\circ}$

AoA $=-3^{\circ}$

(a)

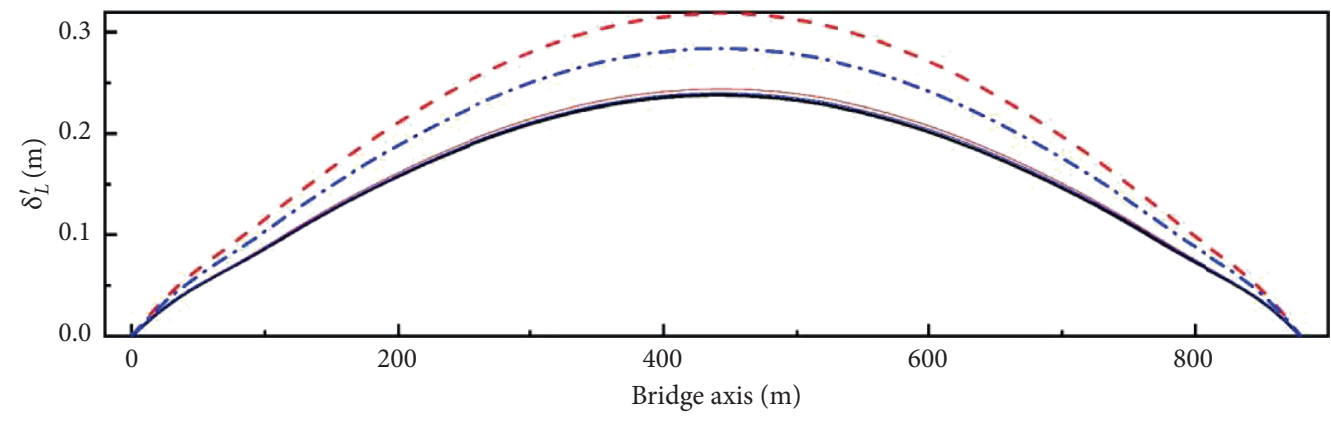
$-\mathrm{AoA}=0^{\circ}$
$--\mathrm{AoA}=+5^{\circ}$
- $\mathrm{AoA}=-5^{\circ}$
$-\mathrm{AoA}=-3^{\circ}$

$\cdot-\cdot \mathrm{AoA}=+3^{\circ}$

(b)

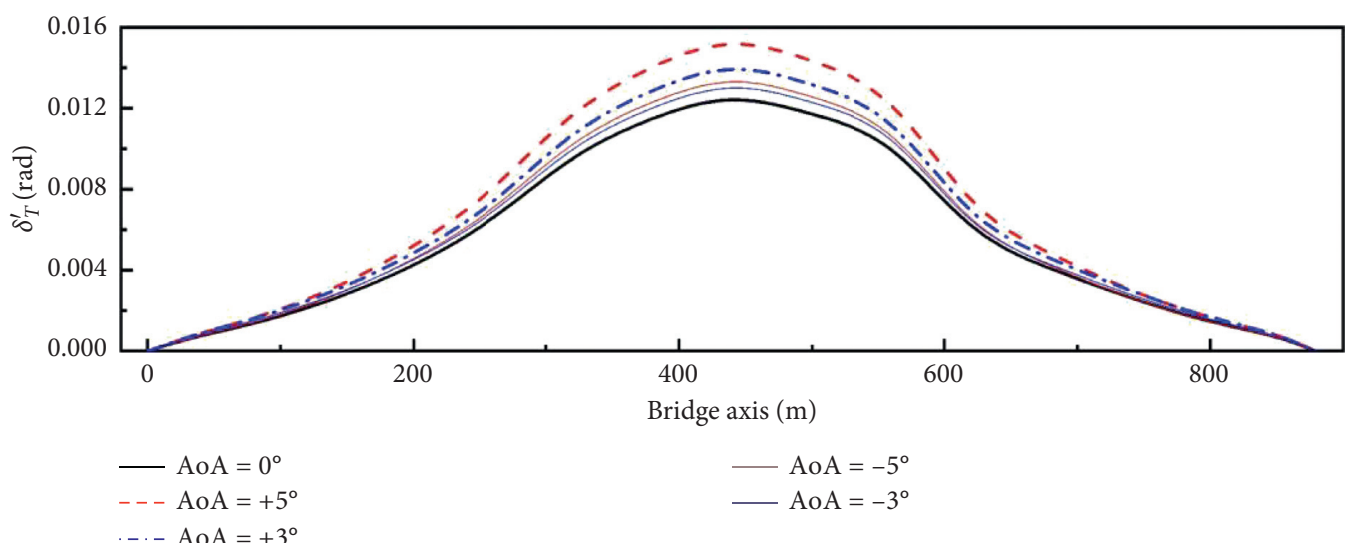

(c)

Figure 17: Effects of AoA on the buffeting responses (Case 1): (a) RMS vertical displacement $\delta_{V}^{\prime}$; (b) RMS lateral displacement $\delta_{L}^{\prime}$; (c) RMS torsional displacement $\delta_{T}^{\prime}$.

where the accuracy of the simulation is validated by comparing the numerical aerostatic forces and experimental ones. The flow patterns around the girder of different cases and at different AoAs are shown in Figure 21.

At $\mathrm{AoA}=0^{\circ}$, the fluid around Case 0 is attached to all surfaces of the girder. However, the addition of subsidiary structures leads to flow separation around Case 1. At AoA $=5^{\circ}$, there is only one separation bubble on the upper surface of Case 0 , whereas the upper surface of Case 1 is fully covered in the separation bubble, and there are also several separation bubbles around the lower surface. At AoA $=-5^{\circ}$, the fluid around Case 0 separates at the leading edge and reattaches to the web, while several small separation bubbles occur on both surfaces of Case 1. According to [23], the aerodynamic behavior of the structure depends on the location, extension, and strength of separated flows and also on the extension of the surfaces exposed to direct impingement by the main flow. Meanwhile, the flow separation causes an increase in turbulent intensity. Therefore, the extended flow separation caused by the subsidiary structures 


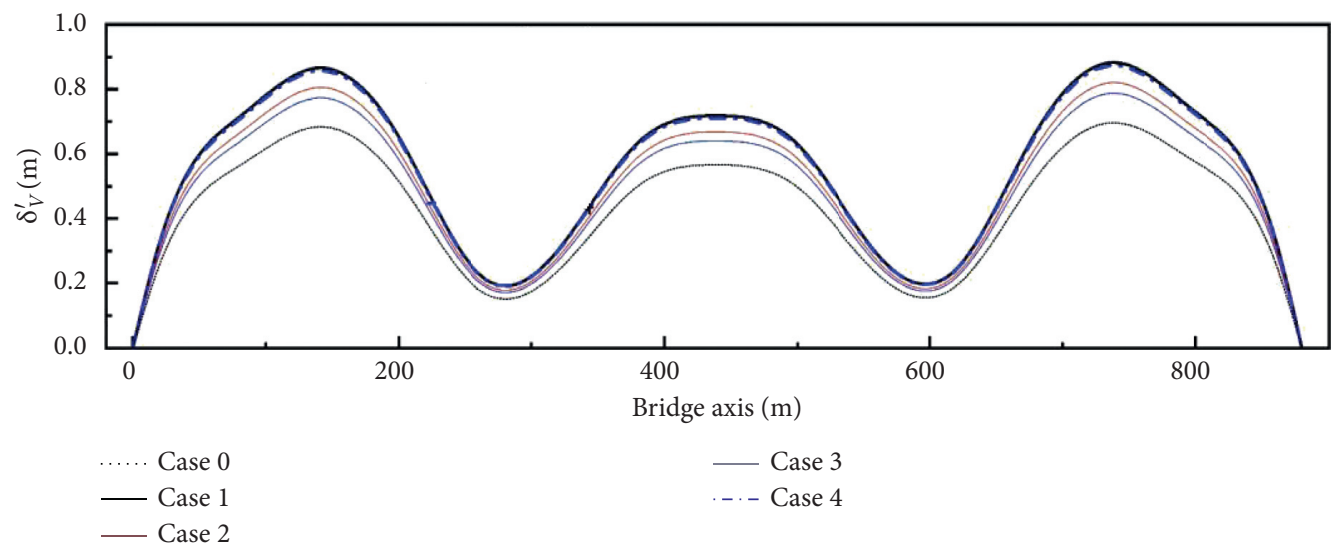

(a)

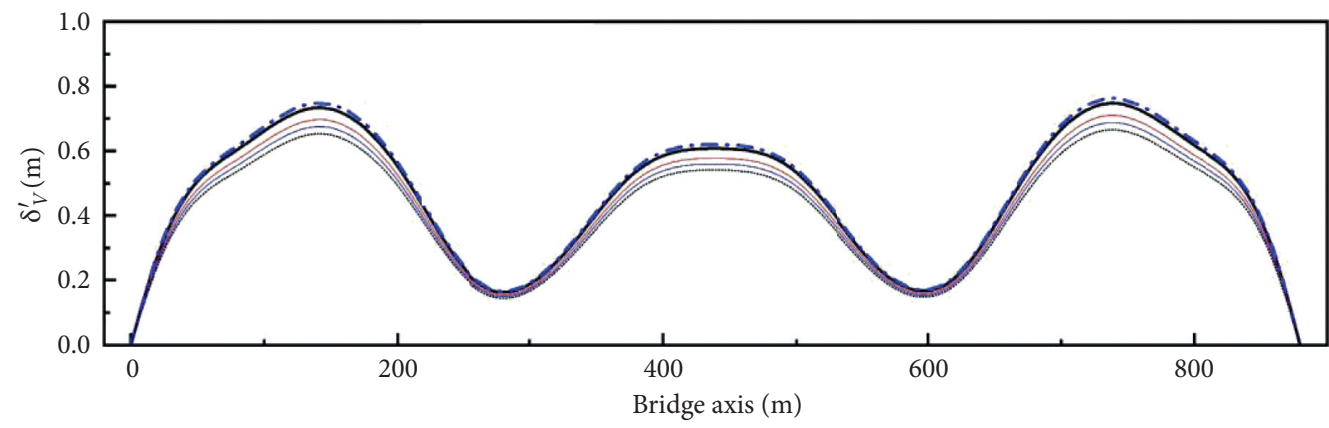
..... Case 0
- Case 1
- Case 3
- - Case 4

- Case 2

(b)

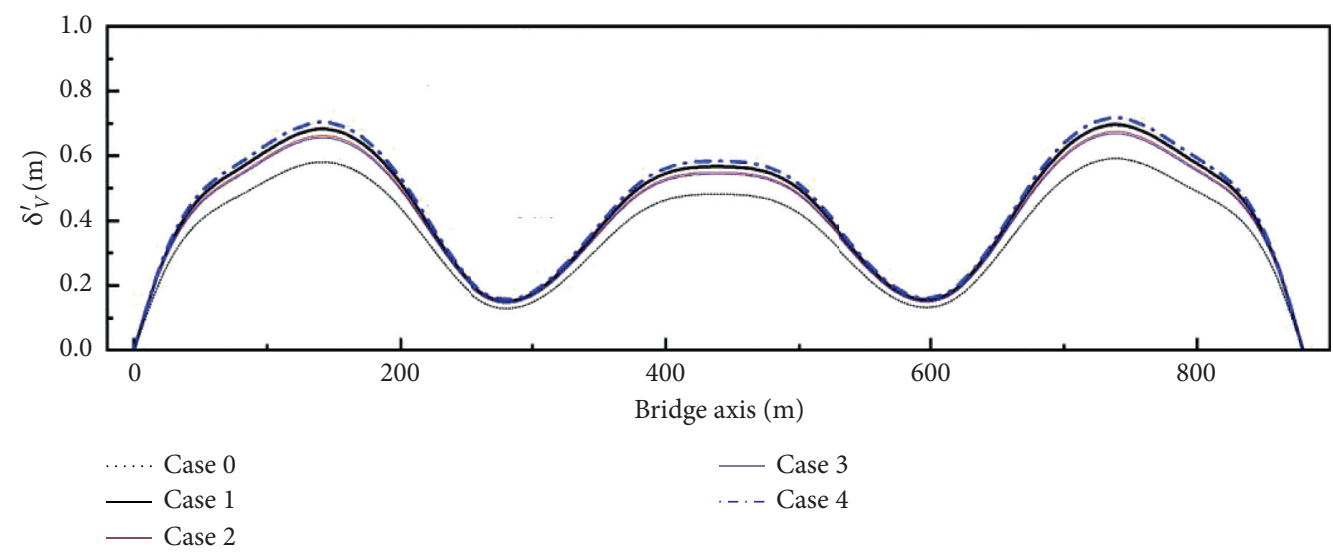

(c)

Figure 18: RMS vertical buffeting displacements of all the investigated cases at different AoAs: (a) AoA $=0^{\circ}$; (b) AoA $=+5^{\circ}$; (c) AoA $=-5^{\circ}$.

could lead to higher wind fluctuations around the girder. Moreover, the fluid around the guardrails and inspection rails is of high vorticity. In such cases, the ambient flow could provide more energy to increase the buffeting responses.

4.4.2. Modification of Pedestrian Guardrails. Having acquired the understanding of the flow field, we can conclude that the flow separation around the girder is mainly caused by the pedestrian guardrails on the upper surface and the inspection rails on the lower surface. It is therefore reasonable that the flow separation could be mitigated by increasing the ventilation rate of the pedestrian guardrail. In the present study, such geometrical modifications are introduced to the original final design (Case 1) for possible suppression of the buffeting responses. As shown in Tables 1 and 2, the pedestrian guardrails of Case 1 are redesigned by changing the horizontal bars and therefore increase the 


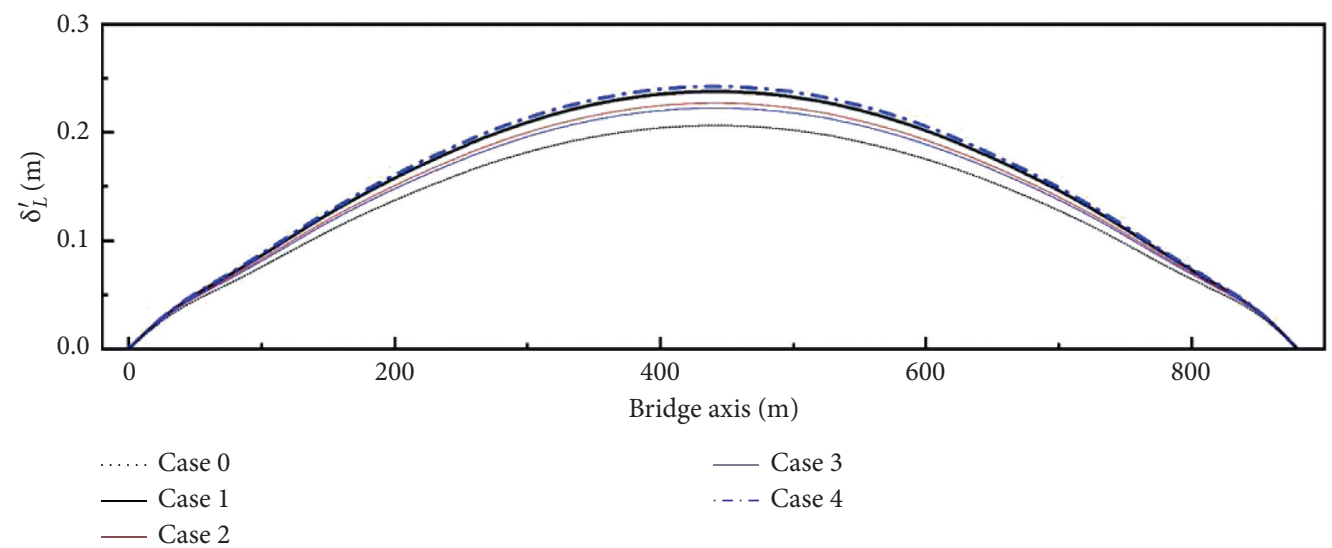

(a)
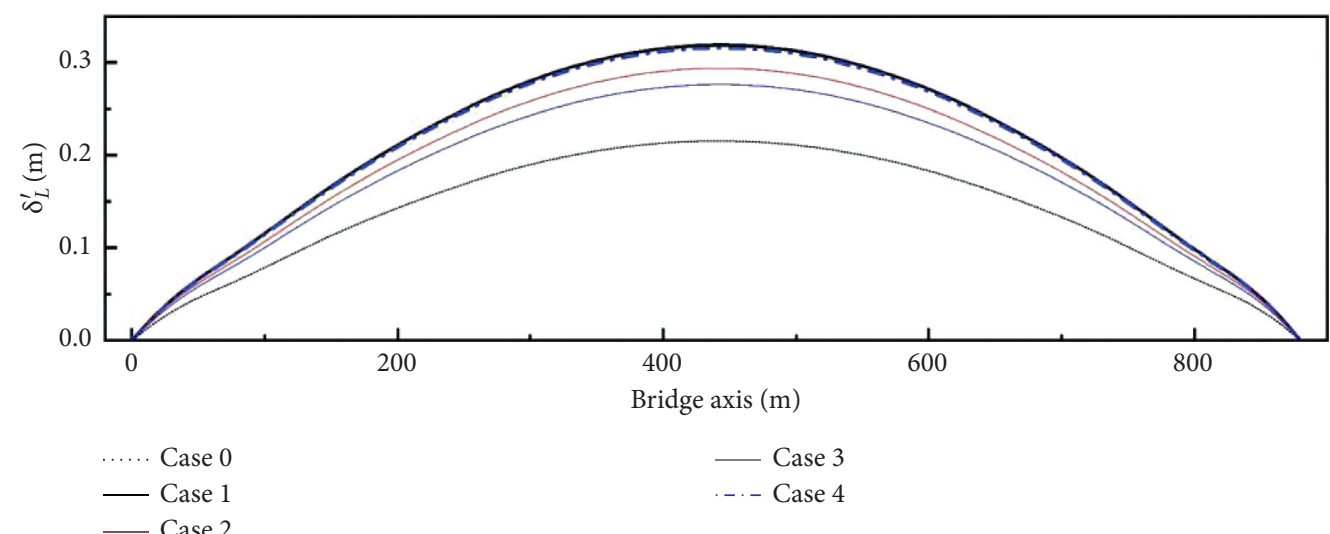

(b)

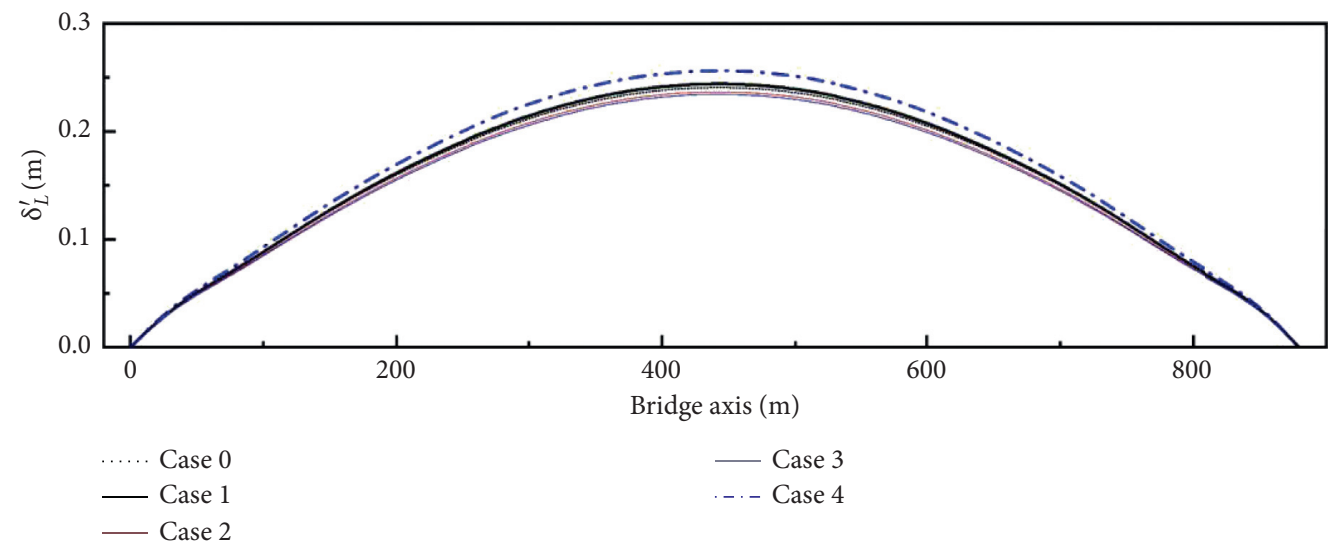

(c)

Figure 19: RMS lateral buffeting displacements of all the investigated cases at different AoAs: (a) AoA $=0^{\circ}$; (b) AoA $=+5^{\circ}$; (c) AoA $=-5^{\circ}$.

ventilation rate from $35.6 \%$ to $59.8 \%$. In this way, the only difference between Case 1 and Case 2 lies in the choice of Type I or Type II pedestrian guardrails.

The vertical, lateral, and torsional buffeting responses of Case 2 have been shown in Figures 18-20, respectively. As presented in the figures, the buffeting responses along the main span can be slightly suppressed at all investigated AoAs when Case 2 is adopted. The comparisons of the results among different AoAs indicate that the control efficiencies will increase when the AoA changes from negative to positive. Regarding AoA $=-5^{\circ}$, the midspan vertical, lateral, and torsional displacements of Case 2 are, respectively, $0.83 \%, 1.77 \%$, and $1.30 \%$ smaller than the those of Case 1 . The corresponding decreases at $\mathrm{AoA}=0^{\circ}$ are $5.00 \%, 4.48 \%$, and $2.17 \%$, while those at $\mathrm{AoA}=+5^{\circ}$ are $7.00 \%, 7.85 \%$, and $4.64 \%$.

The flow fields around Case 2 at different AoAs have been shown in Figure 21. The influential mechanisms of the reduced buffeting responses can be explained by comparing the flow fields of Case 2 and Case 1. Due to the increase of 


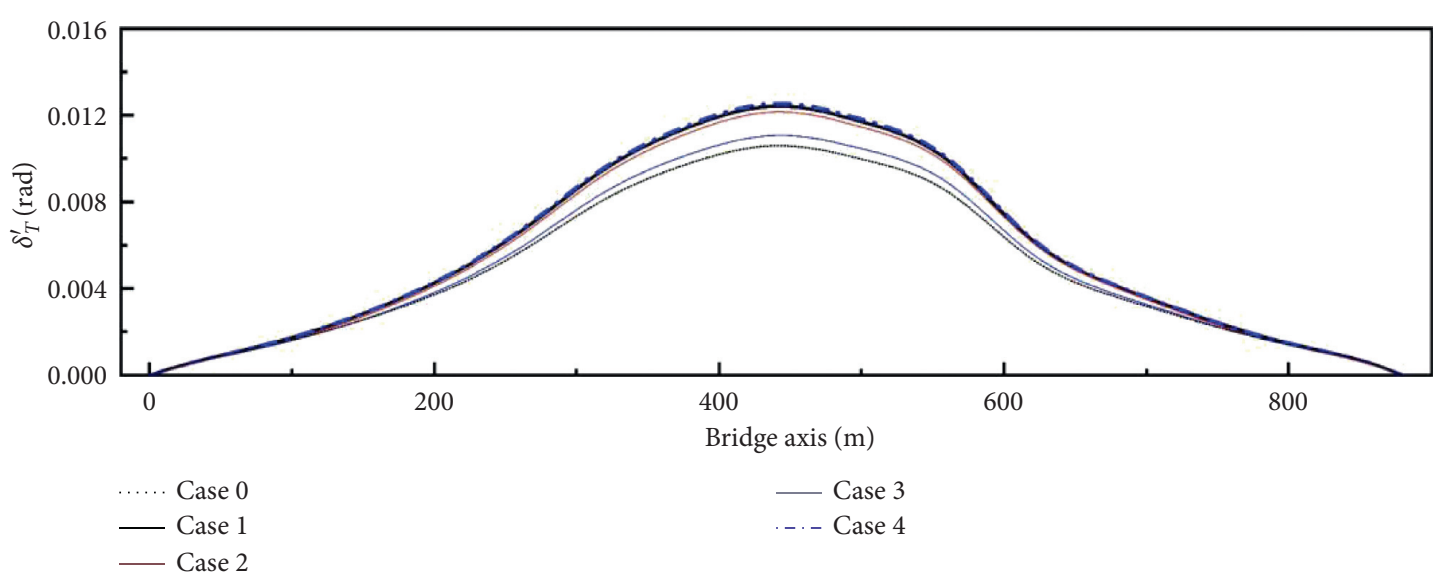

(a)

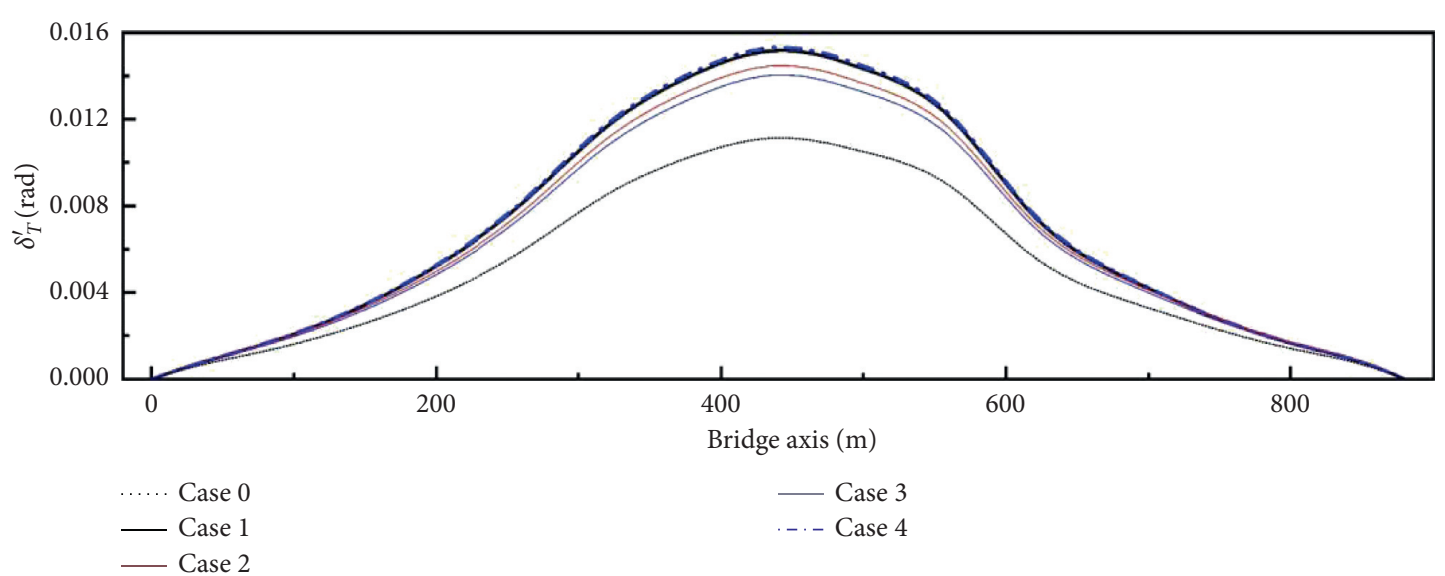

(b)

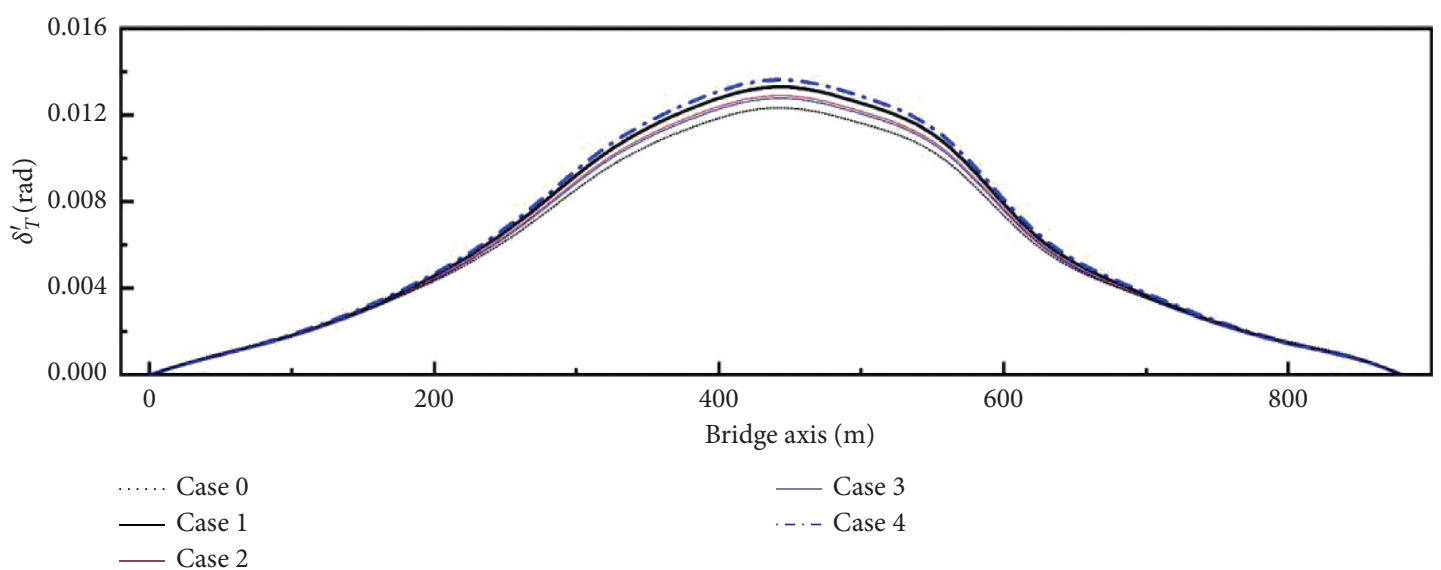

(c)

FIgUre 20: RMS torsional buffeting displacements of all the investigated cases at different AoAs: (a) AoA $=0^{\circ}$; (b) AoA $=+5^{\circ}$; (c) AoA $=-5^{\circ}$.

ventilation rate, the approaching fluid is easier to pass through the gaps inside the guardrails instead of separating over it. As a result, the separation bubbles on the upper surface are significantly squeezed at $\mathrm{AoA}=+5^{\circ}$ and are mostly suppressed at $\mathrm{AoA}=0^{\circ}$. The above phenomena lead to the decreases in buffeting responses. Regarding Case 2 and Case 1 at $A o A=-5^{\circ}$, the flow field on the upper surface is nearly unchanged as the fluid almost attaches to the surface of both cases. Therefore, the buffeting responses at AoA $=-5^{\circ}$ are little changed by increasing the ventilation rate.

4.4.3. Movement of Inspection Vehicle Rails. The inspection rails are essential structures on long-span bridges, which provides the movement of inspection vehicles along the span 


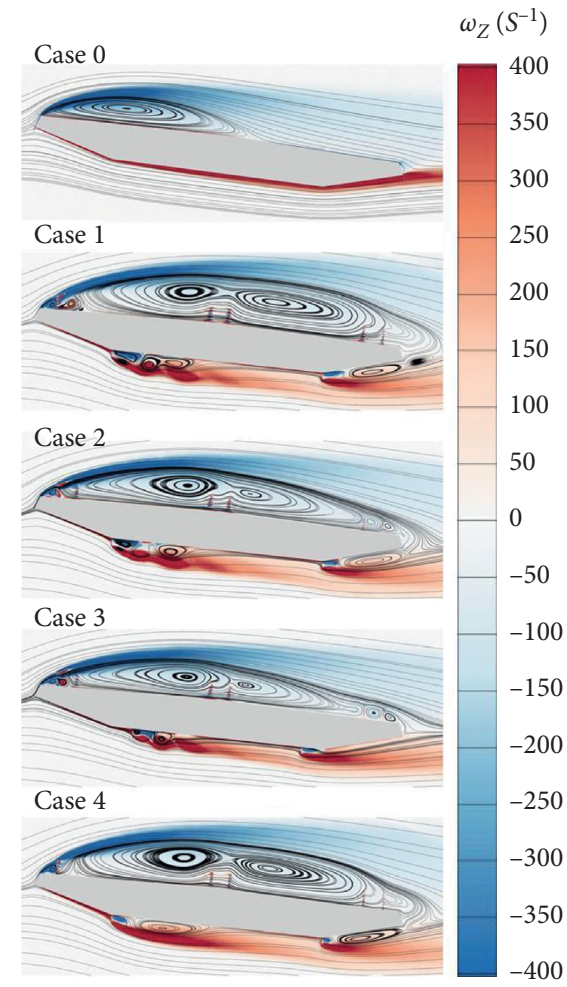

(a)

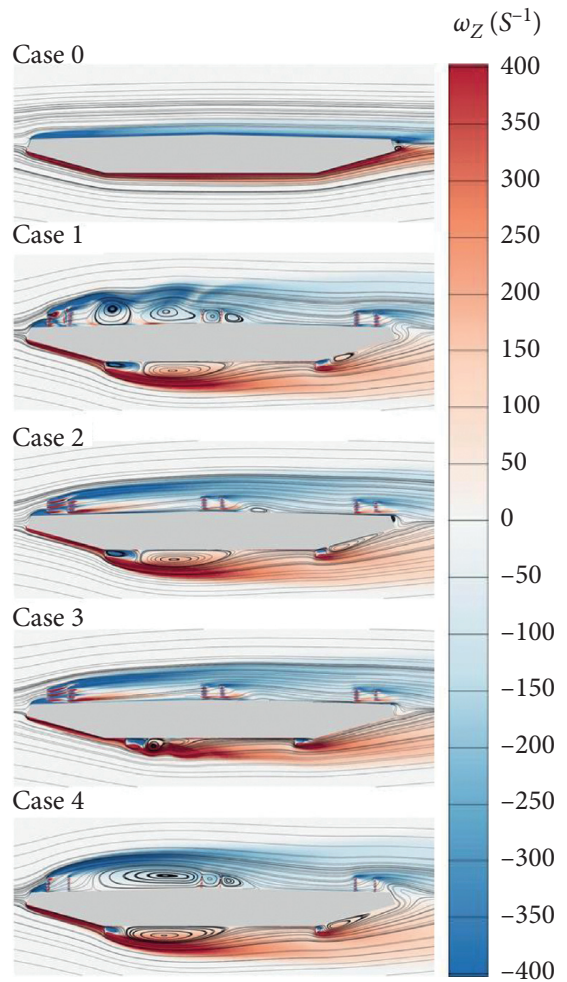

(b)

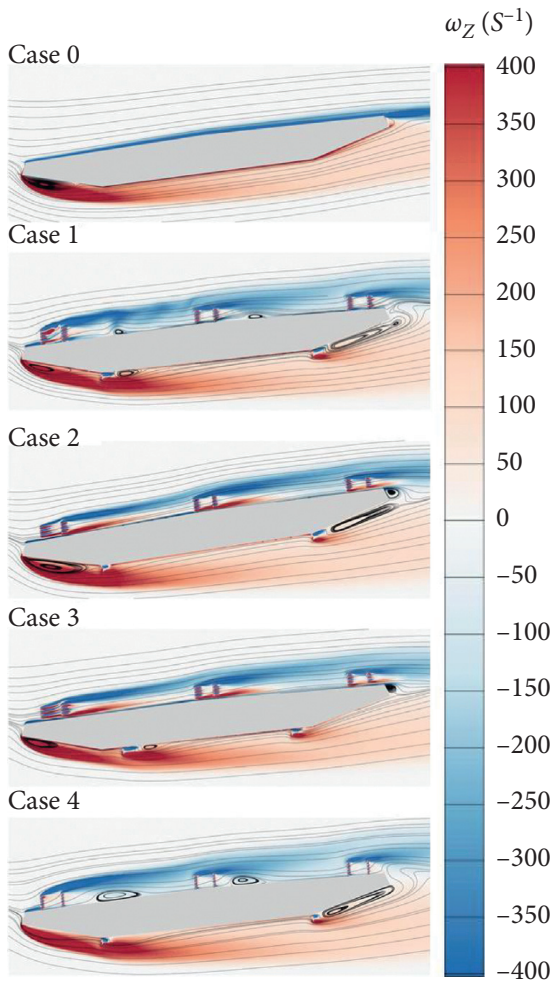

(c)

Figure 21: The flow field of different cases at different AoAs: (a) AoA $=+5^{\circ}$; (b) AoA $=0^{\circ}$; (c) AoA $=-5^{\circ}$. Flow is from left to right; the flow streamlines are colored with vorticity values $\left(\omega_{\mathrm{Z}}\right)$.

for the routine check and maintenance during the operation of the bridge. According to Section 4.4.2, the separated flows on the upper surface are suppressed by increasing the ventilation rate of the pedestrian guardrails. However, such modifications cause little change to the lower ambient flow field. As discussed in Section 4.4.1, the inspection rails can lead to flow separation around the lower surface of the girder. It is reasonable to conjecture that the lower flow separation could be suppressed by moving the inspection rails inward. Therefore, Case 3 configuration $(\mathscr{L}=20 \mathrm{~mm})$ is proposed on the basis of Case 2 configuration $(\mathscr{L}=0)$. The sketch of each case has been shown in Table 1.

The vertical, lateral, and torsional buffeting responses of Case 3 have been shown in Figures 18-20. It can be concluded that the displacements of Case 3 are smaller than the corresponding results of Cases 1 and 2 along the main span and at all investigated AoAs. This indicates that the buffeting responses can be suppressed by Case 3 scheme and the control efficiencies are more prominent than Case 2 scheme. Regarding the control efficiencies by Case 3 at different AoAs, the trends are similar to those by Case 2, which will increase when the AoA changes from negative to positive. At AoA $=-5^{\circ}$, the midspan vertical, lateral, and torsional displacements of Case 3 are, respectively, $1.82 \%, 2.75 \%$, and $2.29 \%$ smaller than the those of Case 1 . The corresponding decreases at $\mathrm{AoA}=0^{\circ}$ are $8.00 \%, 6.39 \%$, and $10.87 \%$, while those at $\mathrm{AoA}=+5^{\circ}$ are $10.72 \%, 13.38 \%$, and $7.50 \%$.
The flow fields around Case 3 at different AoAs have also been shown in Figure 21. The influential mechanisms of the reduced buffeting responses can be explained by comparing the flow fields of Case 3 with those of Cases 1 and 2. The upper flow fields of Case 3 are similar to those of Case 2 at all investigated AoAs, mainly due to the same configurations of pedestrian guardrails. However, the separated flow on the lower surfaces of Case 3 is significantly suppressed compared with Cases 1 and 2. This is mainly because the lower corner of the girder is more streamlined when the inspection rails are moved inward, which allows for the fluid passing adjacent to the lower surface. The above change leads to the reducing buffeting responses at all AoAs.

4.5. Effects of Girder Surface Roughness. During the longterm operation of bridges, the girder surface could become coarser due to physical and chemical damage. In order to identify the influences of the girder surface roughness on the buffeting responses of long-span bridges, the buffeting analysis of Case 4 is carried out and compared with Case 1 at different AoAs. The descriptions of Case 4 have been presented in Section 3.1 and Table 1 , as the roughness level $\mathscr{R}=1.28 \mathrm{~mm}$ is considered based on a 1/60 scaling of the girder.

The vertical, lateral, and torsional buffeting responses of Cases 4 can be seen in Figures 18-20. At $+5^{\circ}$ AoA, the results of Cases 4 are very close to those of Case 1 along the main 
span, which indicates that the girder surface roughness has little influence on the buffeting performance when the AoA is positive. This conclusion can be understood by analyzing the flow field around Case 4, which is also depicted in Figure 21. As seen in the figure, for $\mathrm{AoA}=+5^{\circ}$, the girder surface is covered in the separation bubble and the roughness height cannot affect the ambient fluid directly. Therefore, the flow field of Case 4 at AoA $=+5^{\circ}$ is exactly the same as that of Case 1, which leads to the unchanged buffeting responses.

Meanwhile, the buffeting displacements at $\mathrm{AoA}=0^{\circ}$ and $-5^{\circ}$ are slightly overestimated with consideration of the girder surface roughness. Regarding $\mathrm{AoA}=0^{\circ}$, the midspan vertical, lateral, and torsional displacements of Case 4 are $3.32 \%, 3.26 \%$, and $1.97 \%$ larger than the corresponding results of Case 1. Meanwhile, the influences of girder surface roughness are more prominent at $\mathrm{AoA}=-5^{\circ}$, and the increases at midspan are $3.87 \%, 5.49 \%$, and $2.58 \%$ in the vertical, lateral, and torsional directions. Comparing the flow fields of Case 4 and Case 1 at $\mathrm{AoA}=0^{\circ}$ and $-5^{\circ}$, we find that the increasing buffeting responses can be attributed to the expansions of the separation bubble on the upper surface. This is mainly because the fluid will impinge on the girder upper surface directly, and the consideration of surface roughness can amplify this effect.

\section{Conclusions}

Field measurements, wind tunnel tests, and numerical calculations are utilized to conduct buffeting analysis of a longspan suspension bridge in mountainous urban terrain. The influences of several major aerodynamic parameters, which are usually simplified or even ignored in previous studies, are investigated first to obtain the results from a refinement point of view. Then, an effective countermeasure is proposed to improve the buffeting performances. The following conclusions can be drawn:

(i) The wind field characteristics in the mountainous urban area cannot be accurately described by the Professional Standard PRC [6]. This highlights the necessity of field measurement at the bridge site.

(ii) The experimentally tested AAFs are successfully included in time domain to take into account the unsteady features of buffeting forces. This solves the problem that the AAF can only be utilized in frequency-domain analysis in previous literature.

(iii) Comparing with the results from experimentally tested AAF, the buffeting responses are overestimated without considering AAF or adopting the Sears function. Therefore, the actual AAFs tested in wind tunnel are more appropriate for refined buffeting analysis and can reduce the overall budget.

(iv) Compared with the results from field-measured turbulence power spectra, the buffeting responses from recommended models are underestimated. This will put the structural safety at risk. (v) Comparing the results at $\mathrm{AoA}=0^{\circ}$, the buffeting responses are significantly larger at positive AoAs. At negative AoAs, the vertical displacements are slightly reduced while the torsional displacements are slightly increased. Hence, ignoring AoA will put the structural safety at risk.

(vi) The buffeting responses can be slightly suppressed at all investigated AoAs by increasing the ventilation rate of the pedestrian guardrail. On the basis of the above scheme, moving the inspection rails inward can further decrease the buffeting displacements and the control efficiencies. As a result, the buffeting performances of a long-span bridge are improved by minor geometric modifications while not causing considerable reformulations and extra budget to the initial design.

(vii) The consideration of girder surface roughness shows little influence on the buffeting displacements at positive AoA but causes slight increase at zero and negative AoA.

\section{Data Availability}

The data used to support the findings of this study are available from the corresponding author upon request.

\section{Conflicts of Interest}

The authors declare that there are no conflicts of interest regarding the publication of this paper.

\section{Acknowledgments}

This research was funded by the National Natural Science Foundation of China (NSFC) under grant nos. 51778093 and 51808076, the Science and Technology Research Program of Chongqing Municipal Education Commission under grant no. KJZD-K201802501, and the Graduate Scientific Research Innovation Foundation of Chongqing under grant nos. CYB18022 and CYB17042.

\section{Supplementary Materials}

Supplementary A: more details of the wind field characteristics. Supplementary B: the aerodynamic forces coefficients (AFCs). Supplementary C: the aerodynamic admittance functions (AAFs). (Supplementary Materials)

\section{References}

[1] E. Cheynet, J. B. Jakobsen, and J. Snæbjörnsson, "Buffeting response of a suspension bridge in complex terrain," Engineering Structures, vol. 128, pp. 474-487, 2016.

[2] M. Shinozuka, C.-B. Yun, and H. Seya, "Stochastic methods in wind engineering," Journal of Wind Engineering and Industrial Aerodynamics, vol. 36, no. 90, pp. 829-843, 1990.

[3] G. Deodatis, "Simulation of ergodic multivariate stochastic processes," Journal of Engineering Mechanics, vol. 122, no. 8, pp. 778-787, 1996. 
[4] Y. Cao, H. Xiang, and Y. Zhou, "Simulation of stochastic wind velocity field on long-span bridges," China Civil Engineering Journal, vol. 126, no. 1, pp. 1-6, 1998.

[5] N. N. Minh and T. Miyata, "Numerical simulation of wind turbulence and buffeting analysis of long-span bridges," Journal of Wind Engineering and Industrial Aerodynamics, vol. 83, no. 1-3, pp. 301-315, 1999.

[6] Ministry of Communications of PRC, Wind-Resistant Design Specification for Highway Bridges (Professional Standard Prc), China Communications Press, Beijing, China, 2018.

[7] A. Fenerci, O. Øiseth, and A. Rønnquist, "Long-term monitoring of wind field characteristics and dynamic response of a long-span suspension bridge in complex terrain," Engineering Structures, vol. 147, pp. 269-284, 2017.

[8] A. G. Davenport, "Buffeting of a suspension bridge by storm winds," Proceedings ASCE, vol. 88, no. 3, pp. 233-270, 1962.

[9] N. Isyumov and G. Alan, "Davenport's mark on wind engineering," Journal of Wind Engineering and Industrial Aerodynamics, vol. 104-106, pp. 12-24, 2012.

[10] Z. Q. Chen, Wind Engineering of Bridges, China Communications Press, Beijing, China, 2005.

[11] X. Chen, A. Kareem, and M. Matsumoto, "Multimode coupled flutter and buffeting analysis of long span bridges," Journal of Wind Engineering \& Industrial Aerodynamics, vol. 89, 2001.

[12] H. F. Xiang, Y. J. Ge, L. D. Zhu et al., Modern Theory and Practice on Bridge Wind Resistance, China Communications Press, Beijing, China, 2005.

[13] W. R. Sears, "Some aspects of non-stationary airfoil theory and its practical application," Journal of the Aeronautical Sciences, vol. 8, no. 3, pp. 104-108, 1941.

[14] T. Tao, W. Hao, and W. Teng, "Parametric study on buffeting performance of a long-span triple-tower suspension bridge," Structure \& Infrastructure Engineering, vol. 14, pp. 1-19, 2018.

[15] T. Tao, H. Wang, C. Yao, and X. He, "Parametric sensitivity analysis on the buffeting control of a long-span triple-tower suspension bridge with MTMD," Applied Sciences, vol. 7, no. 4, p. 395, 2017.

[16] Q. Ding, P. K. K. Lee, and S. H. Lo, “Time domain buffeting analysis of suspension bridges subjected to turbulent wind with effective attack angle," Journal of Sound and Vibration, vol. 233, no. 2, pp. 311-327, 2000.

[17] W. S. Han, A. R. Chen, and X. L. Hu, "Verification of timedomain buffeting theory and analysis of influence factors for long-span cable-stayed bridges," China Civil Engineering Journal, vol. 39, no. 6, pp. 66-71, 2006.

[18] Y. U. Honggang, "Time domain analysis of buffeting on shanghai lupu bridge,” Structural Engineers, vol. 25, 2009.

[19] Z. Q. Chen, Y. Han, X. G. Hua, and Y. Z. Luo, "Investigation on influence factors of buffeting response of bridges and its aeroelastic model verification for Xiaoguan Bridge," Engineering Structures, vol. 31, no. 2, pp. 417-431, 2009.

[20] Z. T. Zhang and Z. Q. Chen, "Rationality analysis of some existing aerodynamic admittance models for bridge deck sections," China Civil Engineering Journal, vol. 45, no. 8, pp. 104-113, 2012.

[21] Y. Han, Study on Complex Aerodynamic Admittance Functions and Refinned Analysis of Buffeting Responses of Bridges, Hunan Univeistisy, Changsha, China, 2007.

[22] L. L. Zhang, S. P. Li, and M. S. Li, "Double-exponential generalized coherence model of buffeting forces on streamlined girder," China Journal of Highway \& Transport, vol. 29, no. 11, pp. 65-73, 2016.
[23] D. C. Vaz, R. A. B. Almeida, E. Didier, A. P. V. Urgueira, and A. R. J. Borges, "Improving the aerodynamic performance of vila-real bridge deck-section," Journal of Wind Engineering and Industrial Aerodynamics, vol. 156, pp. 72-83, 2016.

[24] A. Larsen and A. Wall, "Shaping of bridge box girders to avoid vortex shedding response," Journal of Wind Engineering and Industrial Aerodynamics, vol. 104, pp. 159-165, 2012.

[25] Y. Fujino and D. Siringoringo, "Vibration mechanisms and controls of long-span bridges: a review," Structural Engineering International, vol. 23, no. 3, pp. 248-268, 2013.

[26] G. Ming, S. R. Chen, and C. C. Chang, "Parametric study on multiple tuned mass dampers for buffeting control of yangpu bridge," Journal of Wind Engineering \& Industrial Aerodynamics, vol. 89, no. 11, pp. 987-1000, 2001.

[27] B. Wu, L. Zhang, Y. Yang, L. Liu, and H. Li, "Investigation and control of VIVs with multi-lock-in regions on wide flat box girders," Journal of Control Science and Engineering, vol. 2017, Article ID 7208241, 17 pages, 2017.

[28] E. Simiu and N. A. Heckert, "Extreme wind distribution tails: a "peaks over threshold" approach," Journal of Structural Engineering, vol. 122, no. 5, pp. 539-547, 1996.

[29] D. A. Smith and K. C. Mehta, "Investigation of stationary and nonstationary wind data using classical box-jenkins models," Journal of Wind Engineering and Industrial Aerodynamics, vol. 49, no. 1-3, pp. 319-328, 1993.

[30] R. H. Scanlan, "The action of flexible bridges under wind, II: buffeting theory," Journal of Sound and Vibration, vol. 60, no. 2, pp. 201-211, 1978.

[31] G. Diana, S. Bruni, A. Cigada, and E. Zappa, "Complex aerodynamic admittance function role in buffeting response of a bridge deck," Journal of Wind Engineering and Industrial Aerodynamics, vol. 90, no. 12-15, pp. 2057-2072, 2002.

[32] A. Cigada, G. Diana, and E. Zappa, "On the response of a bridge deck to turbulent wind: a new approach," Journal of Wind Engineering and Industrial Aerodynamics, vol. 90, no. 10, pp. 1173-1182, 2002.

[33] G. Diana, F. Resta, A. Zasso, M. Belloli, and D. Rocchi, "Forced motion and free motion aeroelastic tests on a new concept dynamometric section model of the messina suspension bridge," Journal of Wind Engineering and Industrial Aerodynamics, vol. 92, no. 6, pp. 441-462, 2004.

[34] L. Yan, L.-D. Zhu, and R. G. J. Flay, "Identification of aerodynamic admittance functions of a flat closed-box deck in different grid-generated turbulent wind fields," Advances in Structural Engineering, vol. 21, no. 3, pp. 380-395, 2017.

[35] C. Costa, C. Borri, O. Flamand et al., "Time-domain buffeting simulations for wind-bridge interaction," Journal of Wind Engineering and Industrial Aerodynamics, vol. 95, no. 9-11, pp. 991-1006, 2007.

[36] W. Hao, R. Hu, X. Jing et al., "Comparative study on buffeting performance of sutong bridge based on design and measured spectrum," Journal of Bridge Engineering, vol. 18, no. 7, pp. 587-600, 2013.

[37] J. H. G. Macdonald, "Evaluation of buffeting predictions of a cable-stayed bridge from full-scale measurements," Journal of Wind Engineering and Industrial Aerodynamics, vol. 91, no. 12-15, pp. 1465-1483, 2003.

[38] H. Wang, A. Q. Li, and R. M. Hu, "Comparison of ambient vibration response of the runyang suspension bridge under skew winds with time-domain numerical predictions," Journal of Bridge Engineering, vol. 16, pp. 513-526, 2011.

[39] Y. Yang, Y. Gang, W. Fujia et al., "Buffeting performance of long-span suspension bridge based on measured wind data in 
mountainous region," Journal of Vibroengineering, vol. 20, no. 1, pp. 621-635, 2018.

[40] R. Zhou, Y. Yang, Y. Ge, and L. Zhang, "Comprehensive evaluation of aerodynamic performance of twin-box girder bridges with vertical stabilizers," Journal of Wind Engineering and Industrial Aerodynamics, vol. 175, pp. 317-327, 2018.

[41] R. W. Clough and J. Penzien, Dynamics of Structures, Computers \& Structures, Berkeley, CA, USA, 2003.

[42] Q. S. Ding, Refinement of Coupled Flutter and Buffeting Analysis for Long-Span Bridges, Tongji Univeistisy, Shanghai, China, 2001.

[43] M. Massaro and J. M. R. Graham, "The effect of three-dimensionality on the aerodynamic admittance of thin sections in free stream turbulence," Journal of Fluids and Structures, vol. 57, pp. 81-90, 2015.

[44] A. Fenerci and O. Øiseth, "Measured buffeting response of a long-span suspension bridge compared with numerical predictions based on design wind spectra," Journal of Structural Engineeing, vol. 143, no. 9, pp. 1-15, 2017.

[45] M. C. Montoya, F. Nieto, S. Hernández et al., "Computational techniques for novel design of long-span bridges considering aeroelastic phenomena," in Structural Engineering Institute American Society of Civil Engineers Structures Congress 2020, American Society of Civil Engineers (ASCE),, St. Louis MO, USA, 2020.

[46] L. Liu, L. Zhang, L. Zhang, B. Wu, and B. Chen, "Effect of accessory attachment on static coefficients in a steel box girder for long-span suspension bridges," Journal of Engineering Science and Technology Review, vol. 10, no. 1, pp. 68-83, 2017. 